\title{
Intensity fluctuations in Hurricane Irma (2017) during a period of rapid intensification
}

\author{
William Torgerson ${ }^{1}$, Juliane Schwendike ${ }^{1}$, Andrew Ross ${ }^{1}$, and Chris J. Short ${ }^{2}$ \\ ${ }^{1}$ School of Earth and Environment, University of Leeds, LS2 9JT, Leeds, UK \\ ${ }^{2}$ Met Office, FitzRoy Road, Exeter, EX1 3PB, UK
}

Correspondence: William Torgerson (ee16wst@leeds.ac.uk)

\begin{abstract}
Intensity fluctuations observed during a period of rapid intensification of Hurricane Irma (2017) between 04 September and 06 September were investigated in a detailed modelling study using an ensemble of Met Office Unified Model (MetUM) convection permitting forecasts. These intensity fluctuations consisted of alternating weakening and strengthening phases. During weakening phases the tropical cyclone temporarily paused its intensification. It was found that weakening phases were associated with a change in the potential vorticity structure, with a tendency for it to become more monopolar. Convection during strengthening phases was associated with isolated local regions of high relative vorticity and vertical velocity in the eyewall, while during weakening phases the storm became more azimuthally symmetric with weaker convection spread more evenly. The boundary layer was found to play an important role in the cause of the intensity fluctuations with an increase in the agradient wind within the boundary layer causing a spin-down just above the boundary layer during the weakening phases whereas during the strengthening phases the agradient wind reduces. This study offers new explanations for why these fluctuations occur and what causes them.
\end{abstract}

\section{Introduction}

One of the biggest challenges in weather forecasting is predicting when a tropical cyclone (TC) will rapidly intensify. Rapid intensification is defined as a rate of surface wind increase of at least $15.4 \mathrm{~m} \mathrm{~s}^{-1}$ per 24 hours (Kaplan et al., 2010). Most strong tropical cyclones undergo a period of rapid intensification (Kaplan and DeMaria, 2003). Although convection-permitting numerical weather prediction models are capable of producing rapidly intensifying TCs, models still perform poorly when it comes to the timing of rapid intensification events (e.g. Short and Petch, 2018; DeMaria et al., 2021), indicating that the current understanding and representation of intensification processes prior to and during rapid intensification is likely incomplete. Being able to accurately predict rapid intensification events can influence mitigation strategies as the wind speed strongly influences the potential damage the tropical cyclone may cause.

The simplest paradigm for tropical cyclone intensification can be understood by considering the case of a stationary vortex in gradient wind balance. Eliassen (1951) derived the Sawyer-Eliassen equation, that describes the response of the secondary circulation to angular momentum and heat sources. A point heating source located just within the radius of maximum windspeed (RMW) will result in an axisymmetrical response of the secondary circulation, in accordance with the dipolar solutions 
of the Sawyer-Eliassen equation, with most of the streamlines outside the RMW aligning in the radial direction and most of the streamlines inside the RMW in the vertical direction. The result is a drawing in of absolute angular momentum (AAM) surfaces which, in turn, causes an increase in the tangential velocity, and forms a more intense tropical cyclone (Vigh and Schubert, 2009).

The boundary layer spin-up mechanism, as described by Montgomery and Smith (2018), has extended the understanding of intensification mechanisms by examining the role of the highly unbalanced boundary layer. If air parcels spiral inwards towards a tropical cyclone centre fast enough to compensate for frictional AAM loss, then an initially subgradient tangential wind in the boundary layer inflow may become supergradient, allowing the tangential wind within the boundary layer to be higher than the tangential wind above it. The unbalanced mechanism can also spin up the free vortex above the boundary layer through vertical transport of the high AAM air at the top of the boundary layer.

The axisymmetric theory does not fully explain the development of a TC, particularly during rapid intensification, due to the presence of asymmetric processes. These include the role of vortical hot towers (VHTs), which are local small, regions of high relative vorticity and high vertical velocity regions within the eyewall. VHTs and their associated downdrafts can act to transport heat and angular momentum inwards to the eye prior to rapid intensification (Guimond et al., 2010) causing the storm to intensify by warming the eye and increasing the relative vorticity in the region of the VHTs. One other phenomenon not accounted for in the balanced, symmetric paradigm is vortex Rossby waves (VRWs) which are waves that propagate on the radial potential vorticity (PV) gradients in tropical cyclones in a similar way to Rossby waves on planetary scale meridional PV gradients (Montgomery and Kallenbach, 1997). Vortex Rossby waves are capable of inducing barotropic instability within the eyewall which can affect the annular heating distribution and therefore impact on the intensity of the storm (Schubert et al., 1999).

Many of these unbalanced and asymmetric processes have been examined in studies of intensity fluctuations that occur during the intensification of TCs, which are not easily explained by an axisymmetric balanced dynamical theory. One example is vacillation cycles, a form of intensity fluctuations that sometimes occurs during rapid intensification. Nguyen et al. (2011) showed that, during rapid intensification, Hurricane Katrina (2005) exhibited structural changes that caused it to 'vacillate' between monopolar and ring-like states, which also led to short-term intensity changes with the more monopolar states associated with acceleration of the tangential wind well inside the RMW and little intensification near the eyewall. The monopolar and the ring-like states were termed 'symmetric' and 'asymmetric' respectively because the former was associated with a smaller azimuthal standard deviation of PV and the latter a higher azimuthal standard deviation of PV. It should be noted that monopolar vs. ring-like and symmetric vs. asymmetric are independent metrics but are, in this case, correlated. Hankinson et al. (2014) showed that the asymmetric states were associated with radially inward moving isolated PV anomalies. The cause of the asymmetric states was further examined by Reif et al. (2014) who related asymmetric periods to both convective and barotropic instability. Hardy et al. (2021) showed similar processes occurring during the rapid intensification of Typhoon Nepartak (2016) with monopolar states associated with near stagnant tangential wind tendency and weaker eyewall updrafts than in the ring-like phase. Similar changes in structure have been identified in observational data, notably in Kossin and Eastin 
(2001) who identified two regimes with a monopolar and ring-like angular velocity distribution, which also have concomitant monopolar and ring-like equivalent potential temperature distributions.

Another form of intensity fluctuation that can occur in strong TCs are eyewall replacement cycles, where convection associated with outer rainbands develop into a second outer eyewall that gradually moves inwards and replaces the original inner eyewall (Willoughby et al., 1982). Eyewall replacement cycles are known to cause large intensity changes in TCs; however, the RI does not typically resume immediately after the formation of the secondary eyewall, although they are often the cause of cessation of a rapid intensification period, for instance in Hurricane Earl (2010) (Montgomery et al., 2014). Diurnal cycles have also been known to induce intensity fluctuations in TC structure during rapid intensification (Lee et al., 2020; Dunion et al., 2014) although these fluctuations can be explicitly linked to the external environment and have an imposed period of 24 hours.

Hurricane Irma (2017) underwent RI twice (Fig. 1b). During the latter RI event intensity fluctuations have been observed by Fischer et al. (2020) who used observational data to identify two periods of weakening during rapid intensification where the RMW suddenly increased. The two periods of weakening were hypothesised to have different causes but were both linked to lower tropospheric convergence and VRW activity. The intensity fluctuations in Fischer et al. (2020) were subtle (relatively small intensity changes compared to most eyewall replacement cycles), but did involve an expansion of the RMW which, as in the case of a full eyewall replacement cycle, can increase the radius of gale force winds and increase the probability of storm surge, hence motivating a need to understand and be able to predict these forms of fluctuations.

In this paper we analyse the intensity fluctuations of Hurricane Irma using both observations and convection-permitting ensemble simulations to help to understand whether or not the inner core intensity fluctuations are a previously unknown phenomenon or exist on a spectrum that may include vacillation cycles, eyewall replacement cycles or other structural changes that occur during rapid intensification. This will involve investigating the cause of the intensity fluctuations and understanding the structural and dynamical changes of the TC in the transition between a strengthening and weakening phase.

The paper will be organised in the following way: Section 2 will describe the evolution of Hurricane Irma during the relevant rapid intensification period and highlight the structural and intensity changes as well as the track. Section 3 will describe the data used in the analysis, including observations, and the setup of the model simulations. The results are presented in section 4 with discussion in section 4.5. Section 5 generalizes the results across more ensemble forecasts and concluding remarks are given in Section 6.

\section{Synoptic overview of Hurricane Irma (2017)}

Hurricane Irma was the first major hurricane of the 2017 North Atlantic hurricane season. Irma peaked at an intensity of $80 \mathrm{~m} \mathrm{~s}^{-1}$ (1-minute sustained surface wind speeds) with a central surface pressure estimate of $914 \mathrm{hPa}$ early on 06 September before making landfall in Barbuda. A summary of the track of Irma is shown in Fig. 1 along with the best track surface wind speed. 
Irma formed out of an African easterly wave off the west coast of Africa at around $30^{\circ} \mathrm{W}, 17^{\circ} \mathrm{N}$ on 30 August. On 31 August Irma began to rapidly intensify, reaching hurricane strength with a cloud free eye structure and moving in a north westerly direction. This first period of rapid intensification terminated early on the 1 September with an intensity of $50 \mathrm{~m} \mathrm{~s}^{-1}$ at 03 UTC. Irma remained at an intensity of around $50 \mathrm{~m} \mathrm{~s}^{-1}$ during the period from the 01 September to 02 September and did not intensify further due to less favourable environmental conditions. Irma's track also became more southwestward.

The second period of rapid intensification began on 04 September with Irma intensifying from a Category 3 storm ( $945 \mathrm{hPa}$, $\left.50 \mathrm{~m} \mathrm{~s}^{-1}\right)$ at $00 \mathrm{UTC}$ on 04 September to a Category $5 \mathrm{storm}\left(929 \mathrm{hPa}, 75 \mathrm{~m} \mathrm{~s}^{-1}\right)$ at $12 \mathrm{UTC}$ on 05 September. At this time, Irma was in a low wind shear environment with sufficient mid-level tropospheric moisture for intensification and high sea surface temperatures. The influence of the subtropical anticyclone to the north of Irma pushed the storm in a westward direction with a translational velocity of about $5 \mathrm{~m} \mathrm{~s}^{-1}$. A peak intensity of $80 \mathrm{~m} \mathrm{~s}^{-1}$ was reached on 06 September at 06 UTC. Irma made landfall in Barbuda at near peak intensity at 0536 UTC with a minimum recorded sea level pressure of $915.9 \mathrm{hPa}$. During the course of 06 September Irma maintained its intensity and landfall occurred later that day at St. Martin at 1115 UTC and Virgin Gorda at 1630 UTC.

Despite favourable environmental conditions Irma weakened to Category 4 during 07 September due to the start of an eyewall replacement cycle. Irma passed over Little Inagua at 05 UTC on the same day.

Thereafter, apart from a brief period of intensification that occurred around 03 UTC on the 09 September, Irma gradually weakened due to increasing vertical wind shear and eventually land interaction after making landfall in Florida on 11 September. Irma finally dissipated inland on 13 September. Further details on the synoptic overview of Hurricane Irma (2017) are available in Cangialosi and Berg (2018).

\section{Data and Methods}

\subsection{Observational data}

A key source of observational data were aircraft flyovers. Multiple flights were made through Hurricane Irma operated by the National Oceanic and Atmospheric Administration (NOAA). The flyovers were conducted with aircraft from the NOAA aircraft operations centre and the 53rd Weather Reconnaissance Squadron. Observations used from these flights include insitu wind speed and pressure measurements, dropsondes and airborne radar. Satellite visible, infra-red (IR) and morphed integrated microwave imagery (MIMIC; Wimmers and Velden, 2007) provide additional information. Intensity estimates from the Satellite Consensus (SATCON) algorithm using blended data (Velden and Herndon, 2020) are used in conjunction with those from the lower temporal resolution best track data (HURDAT2; Landsea and Franklin, 2013).

The SATCON intensity estimates are derived from the structure of the TC with heavy usage of microwave and satellite IR imagery, so relating structural changes to intensity changes would be a circular argument. Where possible, therefore, MSLP data from flights and dropsondes is also used for short periods where there are a large number of flyovers such as in the afternoon of 05 September. Mean sea level pressure data is preferable to tangential wind data as an intensity proxy, because the latter is strongly dependent on the direction of the flight into the eyewall and the height of the aircraft. 
The dropsonde data is available in a quality-controlled post processed format (in some cases raw data was used instead due to lack of availability). In addition some of the NOAA aircrafts are equipped with C-band and doppler radars on the nose, lower fuselage and tail. The processed lower fuselage and tail radar data is used in the analysis and shows precipitation in dBZ reflectivity. All the processed dropsonde and flight-level data used in this analysis is available from the Hurricane Research division. ${ }^{1}$.

\subsection{Intensity fluctuations in observations}

The focus of the analysis is on the second period of rapid intensification which starts on 04 September at around 00 UTC and finishes around 00 UTC on 06 September (Fig.1b, Fig.2). During the period of rapid intensification the MSLP decreases from around $970 \mathrm{hPa}$ to its minimum value of $914 \mathrm{hPa}$. This rapid deepening is interrupted by two periods of stagnation or slight weakening where the MSLP does not continue to decrease. These periods of weakening are marked by blue bands in Fig.2. The first weakening period starts around 13 UTC on 04 September and lasts for about 12 hours and is followed by a strengthening period from 01 UTC on 05 September until 11 UTC on 05 September. The second weakening period starts around 11 UTC on 05 September and lasts for about 4 hours.

Figure 3 shows observations, from in-flight radar and satellite imagery, of the structural changes just before and after the start of the second weakening period. The convection during the weakening period appears more azimuthally symmetric and continuous as shown in Fig. 3 b compared to Fig. 3a where two regions in the north-west and south-east eyewall have relatively high rainrates. The convection is shallower in the weakening period as indicated by warming cloud tops shown in Fig. $3 \mathrm{~d}$ compared to Fig. 3c. The shallower nature of the convection is also evident in the microwave imagery in Fig. 3e and Fig. 3f. A similar structural change occurs during the first weakening period (not shown) with banded features within the eyewall giving way to broader but shallower convection compared to prior to the weakening period.

\subsection{Numerical model}

An 18-member ensemble of convection-permitting forecasts for Hurricane Irma has been produced using a limited-area configuration of the Met Office Unified Model (MetUM; Cullen, 1993), coupled to the Joint UK Land Environment Simulator (JULES) model for the land surface (Best, 2011; Clark et al., 2011). The ensemble forecast was initialised at 00 UTC 03 September 2017 and run out to four days.

The MetUM solves the fully compressible, deep-atmosphere, non-hydrostatic equations of motion using a semi-implicit, semi-Lagrangian scheme (see Wood et al. (2014) for details). Model prognostic variables are defined on a grid with ArakawaC grid staggering (Arakawa and Lamb, 1977) in the horizontal and Charney-Phillips grid staggering (Charney and Phillips, 1953 ) in the vertical, with a terrain-following vertical coordinate.

Both the MetUM and JULES include a comprehensive set of parametrisation schemes for key physical processes, and the way in which these are configured defines a model science configuration. Here we use the tropical version of the Regional Atmosphere and Land - Version 1 (RAL1-T) configuration presented in Bush et al. (2020), designed for use in km-scale

\footnotetext{
${ }^{1}$ URL: https://www.aoml.noaa.gov/hrd/Storm_pages/irma2017/
} 
regional models in the tropics. We have made one change to the RAL1-T configuration, which is to reduce the air-sea drag at high wind speeds, as motivated by observational data (Powell et al., 2003; Black et al., 2007). This improves the match to the observed wind-pressure relation of tropical cyclones and has since been included in RAL2-T.

The extent of the regional model domain is shown in Fig. 1, and has been chosen so that Irma is located well away from the boundaries at the forecast initialisation time. The horizontal grid spacing is $0.04 \mathrm{deg}$ (approximately $4.4 \mathrm{~km}$ ) in both directions, and there are 80 vertical levels with a horizontal lid at $38.5 \mathrm{~km}$ above sea level (ASL). The model time step is $75 \mathrm{~s}$.

Each member of the convection-permitting ensemble is one-way nested inside a corresponding member of the Met Office global ensemble prediction system, MOGREPS-G (Bowler et al., 2008). The science configuration used in MOGREPS-G is Global Atmosphere 6.1 (GA6.1; Walters et al. (2017)), which was used operationally at the Met Office for global deterministic and ensemble weather forecasting at the time the research was undertaken. The most important difference between GA6.1 and RAL1-T is that convection is parametrised in the former but explicit in the latter. The global model grid spacings are $0.28125^{\circ}$ and $0.1875^{\circ}$ in the zonal and meridional directions (about $31 \mathrm{~km} \times 21 \mathrm{~km}$ in the tropics), respectively. In the vertical there are 70 levels up to a fixed model lid $80 \mathrm{~km}$ ASL. The model time step is $450 \mathrm{~s}$. Initial conditions for each MOGREPS-G member are formed by adding perturbations to the Met Office global analysis, where the perturbations are generated using an ensemble transform Kalman filter (Bishop et al., 2001). The initial state of each MOGREPS-G member is then interpolated to the finer regional grid to provide initial conditions for the nested convection-permitting ensemble member. There is no data assimilation or vortex specification scheme in the regional model itself, but central pressure estimates from tropical cyclone warning centres are assimilated as part of the global model data assimilation cycle (Heming, 2016). Lateral boundary conditions for each convection-permitting ensemble member are provided by the driving MOGREPS-G member at an hourly frequency. The initial SSTs, which differ between perturbed members, are held fixed throughout each forecast.

MOGREPS-G includes two stochastic physics schemes to represent the effects of structural and subgrid-scale model uncertainties: the random parameters scheme (Bowler et al., 2008) and the stochastic kinetic energy backscatter scheme (Bowler et al., 2009). These are not included in the convection-permitting ensemble, so that ensemble spread is generated only by differences in the initial and boundary conditions inherited from the driving model.

\subsection{Diabatic tracers}

Incorporated into the MetUM are two sets of tracers (PV and potential temperature, $\theta$ ) capable of diagnosing diabatic contributions from various parametrisations within the model (Saffin et al., 2016). Examples of this being done previously in extratropical cyclones include, for example, Chagnon et al. (2013). The PV is diagnosed in a semi-Lagrangian way by the tracer such that,

$\frac{\mathrm{D}(\mathrm{PV})}{\mathrm{Dt}}=\sum_{\text {phy }} \frac{\mathrm{D}(\mathrm{PV})}{\mathrm{Dt}}+\sum_{\mathrm{dyn}} \frac{\mathrm{D}(\mathrm{PV})}{\mathrm{Dt}}+\varepsilon$

The change in PV is given by the sum of increments from all physical processes in the first term represented by the subscript phy (namely radiation, microphysics, gravity wave drag, boundary layer diabatic heating and friction and cloud pressure 
rebalancing). There are also dynamical processes in the second term represented by the subscript $d y n$ which include the dynamical solver and mass conservation tracers. Ideally these would be zero and preserve the material conservation of PV. However, approximations in the dynamical core mean that such processes may be non zero. The $\varepsilon$ term represents residuals in the PV budget which may come from truncation errors or non linear interaction effects between the physical tracers. The tracer used most in this analysis is the "initial PV advected" tracer, $\mathrm{PV}_{\text {adv }}$, which can be used to work out what portion of the change in $\mathrm{PV}$ at a particular grid point is due to advection only (i.e. ignoring any change in PV generated by diabatic processes). Every hour the $\mathrm{PV}_{\mathrm{adv}}$ tracer is reset to the diagnosed $\mathrm{PV}$. The change in $\mathrm{PV}$ due to advection at a grid point $(\mathrm{x}, \mathrm{y}, \mathrm{z})$ over the course of an hour is then given by:

$\mathrm{PV}_{\mathrm{adv}}(\mathrm{x}, \mathrm{y}, \mathrm{z}, \mathrm{t}+1)-\mathrm{PV}(\mathrm{x}, \mathrm{y}, \mathrm{z}, \mathrm{t})$.

\subsection{TC centre finding method}

Much of the analysis is done from an axisymmetric perspective in storm relative cylindrical coordinates. Calculations such as this can be highly sensitive to the location of the storm centre. The simplest way to find the TC centre in the model simulation is to find the coordinates that minimize the surface level pressure field. However, meso-vortices within the eyewall often lead to the minimum surface level pressure being displaced from the geometric centre of the eye into the inner eyewall which can cause the tangential flow within the eye to be overestimated and the tangential flow outside the eye to be underestimated. Several more robust methods have been proposed, each with their own advantages and disadvantages. These include finding PV centroids (e.g. Riemer et al., 2010), geopotential height minima (e.g. Stern and Zhang, 2013) or finding the point that maximises tangential wind speed in cylindrical coordinates at its RMW (e.g. Ryglicki and Hart, 2015).

The method used in this analysis balances the need for a consistent and reliable method for finding the location of the TC centre to an appropriate degree of precision, while considering the computational cost of doing so for 18 ensemble members over a 4 day simulation period. The method used here is similar to the one used by Reasor et al. (2013) for flight-level radar data which can also be applied to model fields and uses a simplex algorithm to find the point that maximises the tangential wind within an annulus with a radius equal to the RMW. The simplex algorithm applies geometric transformations to triangles consisting of three points (the simplex) to find the next set of three points. Each point in each simplex is a prospective TC centre where the tangential wind within the RMW annulus can be evaluated. For each iteration in the simplex algorithm the three points will, progressively, increase the tangential wind within the RMW annulus until it is maximised.

The convergence criteria for the algorithm are: no more than 50 function evaluations, an absolute error between iterations of no more than $0.5 \mathrm{~m} \mathrm{~s}^{-1}$ for the function evaluation, and an absolute error of no more than $0.5 \mathrm{~km}$ between points inside a simplex (well under the grid spacing of the model at $4.4 \mathrm{~km}$ ). Some studies (e.g. Bell and Lee, 2012) average an ensemble of solutions based on different initial simplexes; however, it was found that changing the location of the initial simplex did not result in a significantly different TC centre and so a single solution method was used. 


\section{Results}

The fluctuations modelled during rapid intensification in Hurricane Irma have similarities to both vacillation cycles and eyewall replacement cycles but with important differences that will be discussed in detail.

\subsection{Model simulation of intensity fluctuations}

The second period of rapid intensification in Hurricane Irma is broadly captured by the convection-permitting ensemble forecasts (Fig. 1). One of the ensemble members (ensemble member 15) was analysed in detail as it was judged to be most representative in terms of the size of the RMW, the surface wind speed, mean sea level pressure and track, in comparison to the observations. Fig. 4 shows how the MSLP and surface wind speed change in this ensemble member in addition to the RMW. The modelled MSLP is slightly higher than the NOAA best track values but the rate of deepening is captured well with the rapid intensification occurring at the correct time. Even with the reduced drag at high wind speeds the wind-pressure relation in the model is too steep (wind speeds too slow for a given central pressure) and consequently the wind-speed is underestimated compared to observations once RI occurs. However, the timing of the rapid intensification and its cessation is accurate. The track of this forecast and the other ensemble members are shown in Fig. 1 and all agree reasonably well with the best track.

By examining the change in the wind speed, MSLP and RMW over time (Fig. 4) the development of the TC has been split into distinct phases. The pre-fluctuation rapid intensification phase covers the first 45 hours of the simulation. During this time, after an initial model spin-up period, the storm intensifies nearly monotonically; the wind speed increases rapidly at all levels, the MSLP decreases and the RMW contracts. During weakening phases (blue bands in Fig. 4) the MSLP stagnates or increases, the maximum surface total wind speed decreases and the RMW expands. The opposite occurs in the strengthening phases (red bands in Fig. 4).

The maximum tangential wind, particularly near the top or just above the boundary layer (e.g. at $1532 \mathrm{~m}$ ) also exhibits these fluctuations but does lag behind compared to higher levels (e.g. at $3002 \mathrm{~m}$ ) where the maximum tangential wind follows a similar pattern to the surface total wind speed. This is also true of the expansion of the RMW, with the increase in the RMW happening at $1532 \mathrm{~m}$ (dark green line) prior to the increase in the surface RMW (aqua line). At the surface, the signal in the tangential wind speed is weaker compared to at higher levels. The role the radial flow plays in modifying the total surface windspeed during the fluctuations, and the reason for the tangential wind spin-down preceding a weakening phase is explored in detail in Section 4.4 .

The simulation shows four weakening periods and three strengthening periods which are defined in terms of surface wind speed, surface RMW and MSLP. There is also an uninterrupted period of intensification prior to these fluctuations. During the period of intensity fluctuations from 45 hours to 84 hours Irma is still rapidly intensifying overall, so the brief interruptions in intensification do not stop rapid intensification from happening. The main aim of the analysis is to determine why these intensity fluctuations happen during this period of rapid intensification, the mechanisms behind them and any structural changes with which they are associated. 
It should be noted that during the analysed rapid intensification period Hurricane Irma was a fairly symmetric storm under low vertical wind shear with environmental factors playing a minimal role in these fluctuations. Changes in vertical shear, translation speed, sea surface temperature, maximum potential intensity and the diurnal cycle of convection are not correlated with the intensity fluctuations (not shown).

\subsection{Barotropic structural changes}

\subsubsection{PV symmetry and structure}

Distinct structural changes took place during the strengthening and weakening phases of Hurricane Irma. Fig.5 and Fig.6 show the PV field from a horizontal (just above the boundary layer where the change is most visible) and azimuthally-averaged perspective with times selected to best illustrate the evolution of the PV from just prior to the start of a weakening phase to the end of the weakening phase and start of the next strengthening phase. The evolution during the strengthening phases is less dramatic and is not shown. Prior to each weakening phase the PV field is ring-like and elliptical (Fig. 5a, f, k, p). This elliptical PV field becomes more circular at the start of each weakening phase (Fig. 5b,g,l,q). The PV field also becomes more monopolar during a weakening phase with higher PV in the centre of the storm and lower PV in the eyewall. A comparison of Fig. 6a,f,k,p with Fig. 6b,g,l,q shows that the transition from a ring-like to a more monopolar PV structure at the start of the weakening phase occurs primarily just above the boundary layer especially between $1 \mathrm{~km}$ and $2 \mathrm{~km}$ height. The trend towards a more monopolar distribution continues to the middle of the weakening phases where a ' $\mathrm{C}$ ' shaped ring of high PV (Fig. 5c,h,m,r) develops near the TC centre above the boundary layer (Fig. 6c,h,m,r). The PV within the boundary layer also declines but maintains a more ring-like structure. The end of the weakening phase is characterised by the upward movement of the high PV zone at around $2 \mathrm{~km}$ height in the eye (Fig. 6d,i,n,s), and re-formation of a weak, circular, PV ring above the boundary layer (Fig. 5d,i,n,s). The start of the strengthening phase roughly coincides with the strengthening of this new PV ring (Fig. 5e,j,o,t) which becomes increasingly elliptical during the strengthening phase. The elliptical to circular transitions are particularly prominent in W1 and W4 which are more pronounced weakening phases than W2 and W3.

Figure 7a summarises these PV structure changes throughout the simulation with an index that describes how monopolar or ring-like the PV distribution is above the boundary layer (Hardy et al., 2021). Higher values of the ratio $\mathrm{PV}_{0} / \mathrm{PV}_{\max }$, where $\mathrm{PV}_{0}$ is the layer averaged $\mathrm{PV}$ at the centre of the storm and $\mathrm{PV}_{\max }$ is the maximum layer averaged $\mathrm{PV}$, imply the vorticity structure is more monopole-like while lower values imply the structure is more ring-like.

During the weakening phases there is a trend for the PV structure to become more monopolar. At the end of each weakening phase the trend suddenly reverses and the vorticity structure becomes more ring-like. The change in the tendency of the vorticity structure is very sudden and coincides exactly with the start and end of each phase. However, as indicated by Fig. 6 the PV distribution does not change uniformly at all heights. At lower levels closer to the boundary layer the PV field is more monopolar at the beginning of the weakening phase, while at higher levels it lags behind and is more monopolar at the start of the next strengthening phase. Note how the storm is continually transitioning away from or towards a ring-like structure. This behaviour is different to intensity fluctuations associated with vacillation cycles where the storm can remain in the monopolar 
https://doi.org/10.5194/wcd-2021-81

Preprint. Discussion started: 3 January 2022

(c) Author(s) 2022. CC BY 4.0 License.

Weather and

Climate Dynamics

Discussions

L.

state for 10 hours or more (Hardy et al., 2021). It should be noted that the more dramatic weakening phases, W1 and W4 shown in Fig. 5a-e,p-t and Fig. 6a-e,p-t are associated with a more pronounced realignment of PV both in terms of the ring becoming more monopolar and an overall decrease in PV between Fig. 5 c,r and Fig. 5 d,s. Fig. 7a shows a much bigger increase in $\mathrm{PV}_{0} / \mathrm{PV}_{\max }$ for $\mathrm{W} 1$ and $\mathrm{W} 4$ compared to $\mathrm{W} 2$ and W3. This is also seen in Hardy et al. (2021) with a greater change in $\mathrm{PV}_{0} / \mathrm{PV}_{\max }$ associated with a more dramatic intensity fluctuation. Other metrics that describe the barotropic structure (Fig. 7b-d) also show a more pronounced change during W1 and W4 compared to W2 and W3. It is well understood that annular vorticity rings can only be maintained by constant diabatic forcing and that without this the rings will be unstable and the vorticity will be redistributed into a monopole like structure (e.g. Prieto et al., 2001; Nguyen et al., 2011). The change in this PV distribution is likely due to PV being transported from the eyewall into the eye. To demonstrate this PV transport Fig. 8 shows the PV tendency due to radial and vertical advection only over the previous hour. The start of the weakening phase shows PV transported to the eye at T+45 h (Fig. 8a). At T+48 h (Fig. 8b) the PV transport occurs above the boundary layer including at the 1532- $\mathrm{m}$ level shown in Fig. 5. At T+45 h the transport of PV into the eye at this level is weak with different azimuthal starting points in the trajectories leading to rather different end points. Therefore, the gain of PV within the eye is due to eddies transporting more PV inwards than outwards. By $\mathrm{T}+48 \mathrm{~h}$ there is a more distinct vertical transport of PV in the eye from the boundary layer. So, the change to a more monopole structure can be explained by an initial inward asymmetric radial transport of PV within the eye followed by the development of a very weak (on the order of $0.02 \mathrm{~m} \mathrm{~s}^{-1}$ ), deep ascent layer, transporting PV slowly upward. PV is also transported radially inward in the eye although the radial transport is weak (trajectories in Fig. $8 b$ ). The weak ascent that develops within the eye originates within the eyewall and gradually extends inwards into the eye (not shown). The upward vertical motion is weak and inconsistent, only becoming apparent when 10-minute data is averaged over an hour. The PV contribution from diabatic processes other than large scale transport, during the weakening phase, is negative indicating the entire positive PV tendency is linked to movement of PV into the eye. The negative PV tendency regions in Fig. 8 are caused by the loss of PV through the updraft in the eyewall. There is also a gain of PV advected near the surface particularly at $\mathrm{T}+48 \mathrm{~h}$ (Fig. 8b) which can be linked to an increase in the inflow within the eye region and transport of frictionally generated $\mathrm{PV}$ from greater radii.

In addition to the radial PV structure the PV also varies azimuthally with the intensity fluctuations. One way of describing the azimuthal PV symmetry is the method of Nguyen et al. (2011) and Reif et al. (2014), where the azimuthal standard deviation of PV is calculated at each radius and the maximum value is taken. A high standard deviation of PV implies a less azimuthally symmetrical storm. It should be emphasised that this is a separate metric not related to the radial distribution of PV (i.e monopolar and ring-like distributions). In the case of Nguyen et al. (2011) for example, the radial and azimuthal measures of PV were used interchangeably to describe 'symmetric' or 'asymmetric' states (the ring-like PV distribution in Nguyen et al. (2011) was correlated to an azimuthally symmetric state which is not the case here). In this study, references to symmetry only refer explicitly to variations in the azimuthal distribution of PV.

Figure $7 b$ shows how this metric varies throughout the simulation. The red curve shows that the change in the variation of azimuthal PV at the RMW follows a similar pattern to the maximum azimuthal PV (black line). At the start of a weakening phase the maximum azimuthal standard deviation of PV decreases rapidly or becomes more azimuthally 'symmetrical' with 
the inverse happening during strengthening phases. The weakening phases are, therefore, characterised by more azimuthally symmetric, more monopolar PV fields while the strengthening phases are characterised by a less azimuthally symmetric, more ring-like PV distribution. The azimuthal symmetrisation of the PV field occurs at approximately the same time that the field becomes more monopolar. This contrasts with prior work on vacillation cycles (e.g. Nguyen et al., 2011) where a more azimuthally symmetric PV field in Hurricane Katrina (2005) was associated with a ring-like distribution of PV. The change in the azimuthal symmetry is also described in Fig. 7c which shows that during the strengthening phases the initially circular PV rings become increasingly more elliptical (higher eccentricity) confirming that the start of a weakening phase is associated with a rapid change from an elliptical PV ring to a more circular one (also seen in Fig. 5).

To attempt to explain the causes of the change in PV structure the barotropic conversion rate was computed (as in Hankinson et al., 2014). The barotropic conversion rate describes how kinetic energy is transferred between eddies and the mean flow. Hankinson et al. (2014) showed that the conversion rate, in their simulation, is always negative which implies a conversion of kinetic energy between the mean state and the eddy state.

Figure $7 \mathrm{~d}$ shows the barotropic conversion rate as a function of time. The beginning of the weakening phase is accompanied by a distinct rise in the barotropic conversion rate (it becomes less negative) while the commencing of the strengthening phase is associated with a more negative conversion rate. As the strengthening phases are associated with a less symmetric PV structure more kinetic energy is transferred from the mean state to the eddy state. The start of a weakening phase is therefore associated with a rapid reduction in the amount of kinetic energy transferred away from the mean state to the eddy state.

\subsubsection{Vortical hot towers}

During the strengthening phases, VHT-like features are apparent as small-scale local regions of high vorticity and vertical velocity within the eyewall. These features resemble VHTs, formally defined in Smith and Eastin (2010), with local maxima in perturbation vertical velocity and with significant vertical depth albeit with lower values in these quantities (weaker and shallower). These structures appear frequently and may play a significant role in the development of the cyclone. Since they look like VHTs but are not strong or deep enough to meet the criteria for a VHT they will simply be described as VHT-like structures.

Figure 9 shows perturbation vertical velocity and relative vorticity at different heights at the same times as in Fig. 5. The VHT-like structures are more likely to be present during strengthening phases (particularly towards the end of the strengthening phases) and rarely form during weakening phases although an already existing VHT-like structure may persist for a couple of hours into the weakening phase. These structures typically last on the order of an hour which is a little shorter than the lifespan of convective structures found by Yeung (2013) during the rapid intensification of Typhoon Vicente. The VHT-like structures move anticlockwise, with the flow, near the RMW. Filaments of high pertubation vertical velocity, but relatively low pertubation relative vorticity, associated with inner rain-bands, also commonly emanate outward from these VHT-like structures (see, for example Fig. 9p north of the RMW). It is fairly common, within the strengthening phases, to see two VHT-like structures at once which typically are 180 degrees from each other. In this case one VHT-like structure tends to be much stronger than the 
other. An example of this is shown in Fig. 9a with the VHT-like structure in the southwest quadrant being more intense and deeper than the one in the northeast quadrant.

During the weakening phases VHT-like structures rarely form such that in the middle of a weakening phase it is unusual to see one of these structures. The T+72.2 h panel (Fig. $9 \mathrm{~m}$ ) does show a weak, shallow, VHT-like structure in the northwest quadrant though it should be noted that W3 is the weakest weakening phase. Towards the end of a weakening phase VHTlike structures may redevelop and often form outside of the RMW. The T+50.7 h panel (Fig. 9d) shows signs of a VHT-like structure on the eastern side of the TC outside of the RMW that forms before moving inwards. If Fig. 9 is compared to Fig. 5 it can be seen that the VHT-like structures are typically located at the two points on the elliptical PV rings furthest away from the centre (i.e. along the semi-major axis of the PV elliptical ring). The strongest VHT-like structures tend to form just prior to a weakening phase and may last for the first few hours of the weakening phase. The VHT-like structure in Fig. 9a,p are examples of particularly strong VHT-like structure that occur just prior to the W1 and W4 phases respectively but are shown to very quickly dissipate during the start of W1 and W4 respectively (Fig. 9b,q). The regions of locally high vertical velocity and relative vorticity associated with the VHT-like structures becomes increasingly de-localized and distributed over the entire eye-wall region resulting in a more axi-symmetric structure. Any regions of high pertubation vorticity or vertical velocity that form during the weakening phases are much weaker and shallower than the VHT-like structures that form during the strengthening phases (such as the low-level region of high relative vorticity north-west of centre in Fig. 9m) or occur well outside of the RMW (such as the updraught south-east of centre in Fig. 9r).

\subsubsection{Tangential wind budget}

The spin-up of a TC can be examined in terms of the tangential wind budget which describes contributions to the mean tangential wind tendency from radial and vertical advection of absolute angular momentum, which can be further split up into mean and eddy contributions. A form of the tangential wind budget based on Persing et al. (2013) is:

$\frac{\partial \bar{v}}{\partial t}=-\bar{u} \overline{(f+\zeta)}-\bar{w} \frac{\partial \bar{v}}{\partial z}-\overline{\left(u^{\prime} \zeta^{\prime}\right)}-\overline{\left(w^{\prime} \frac{\partial v^{\prime}}{\partial z}\right)}+F$,

where $v$ is the tangential wind, $u$ is the radial wind, $w$ is the vertical velocity, $f$ is the Coriolis parameter, and $\zeta$ is the relative vorticity. Overbars represent azimuthal averages of these terms while primes represent perturbations from the azimuthal average. The terms on the right hand side of the equation from left to right are: mean radial vorticity flux, mean vertical advection of absolute angular momentum, eddy radial vorticity flux and vertical eddy advection of absolute angular momentum. The final term, $F$, represents sub-grid frictional contributions to the budget which are negligible outside of the boundary layer.

In order to understand the contribution of the VHT-like structures to the spin-up or spin-down of the TC, the eddy and mean contributions to the tangential wind budget were examined. Fig. 10 shows the contributions to the tangential wind budget through mean and eddy radial vorticity fluxes and vertical advection of AAM. Near the eyewall, the mean term has a positive contribution to the tangential wind in the boundary layer due to the radial inflow and a negative contribution above the boundary 
layer where the boundary layer outflow jet is (Fig. 10a,c). The larger positive contribution to the tangential wind in the boundary layer, and larger negative contribution above the boundary layer in S1 compared to W1 is attributed to a stronger inflow and outflow in and above the boundary layer respectively.

Just above the boundary layer the eddy term has a positive contribution to the tangential wind budget in both S1 and W1 (Fig. 10 b,d). However, in $\mathrm{S} 1$ the magnitude of the positive eddy contribution above the boundary layer (around $1500 \mathrm{~m}$ ) is larger. This finding is robust across all strengthening and weakening phases and extends generally to other ensembles that show these intensity fluctuations (see Section 5). The greater positive contribution, to the tangential wind, of the eddies just above the boundary layer during the strengthening phases is associated with VHT-like activity. These results are illustrated in Fig. 11 which shows during the 45.5 hour to 57.5 hour period (comprising both W1 and S1 periods) a composite of all times where there is either no VHT activity (Fig. 11 a,b) or strong VHT activity (Fig. $11 \mathrm{c}, \mathrm{d}$ ). In total there were 12 times where strong VHT activity occurred and 10 times where no VHT activity occurred during this period. This allows the effect of the VHT-like structures to be analysed more directly. As can be seen by comparing Fig. $11 \mathrm{~b}$ and d VHT-like structure activity is associated with an increased positive tangential wind tendency from the eddy terms just above the boundary layer compared to times without VHT activity. This is despite the increase in the negative contribution from the mean flow (Fig. 11 a,c). It is harder to say if the association between VHT-like structures and an increased eddy positive wind tendency above the boundary layer is causal and may instead be related to the relative frequency of VHTs during weakening phases compared to strengthening phases. Times during S1 with VHT activity (not shown) were associated with greater eddy tangential wind tendency compared to times during S1 without VHT activity but the effect was small.

However, the radial location of the VHT-like structure seems to be important, the VHT-like structure inside the RMW in Fig. 9p is concurrent with an eddy effect that spins down the eyewall (negative contribution to the tangential wind budget) and spins-up the eye (not shown). Likewise the VHT-like structure in Fig. 9t is associated with a positive eddy tangential tendency outside the eyewall and a spin down within the eyewall. VHT-like structures may have the ability to change the PV structure of the storm by stirring in higher PV from the eyewall into the eye which can spin up the eye (e.g. Hankinson et al., 2014) and induce a transition from a ring-like to monopole PV structure.

\subsection{Convective structural changes}

To understand how the convective structures change with the intensity fluctuations the diabatic heating profiles are investigated, in particular, how the heating profiles change from strengthening phases transitioning to weakening phases. The diabatic heating (Fig. 12 and 13) is calculated using Eularian potential temperature increments directly output from the MetUM.

During both weakening and strengthening phases there are some similarities, notably two separate heating maxima, one in the inflow boundary layer at around $1 \mathrm{~km}$ and the other in the mid-troposphere associated with the latent heat release above the freezing level in the free vortex at around $7 \mathrm{~km}$. The majority of the heating occurs around the RMW in the eyewall, although small amounts of heating also occur out to $150 \mathrm{~km}$ associated with outer rainbands.

All of the weakening phases have a heating distribution with a greater radial extent compared to all of the strengthening phases (not shown). This can also be seen in the observations in Fig. 3 a,b which shows the convection in the eyewall appearing 
to thicken with the moderately high precipitation rates occupying a greater radial extent during a weakening period than just prior to it. The overall heating rates are substantially weaker during the middle of the weakening phases compared to the strengthening phases (e.g. a maximum of around $30 \mathrm{~K} \mathrm{~h}^{-1}$ in the middle of W1 compared to around $45 \mathrm{~K} \mathrm{~h}^{-1}$ at the start of S1) with substantial heating occurring outside the RMW. In the strengthening phases the heating is concentrated in a narrow band (of around $10 \mathrm{~km}$ width) just inside the RMW, while in the weakening phases the heating maximum is shifted outside of the RMW. Just above the boundary layer there is a heating maximum in both the strengthening and weakening phases, the heating here is stronger in the strengthening phases but is located inside the RMW during both the weakening and strengthening phases. The dominant component of diabatic heating, just above the boundary layer is from the latent heating due to cloud formation at the top of the boundary layer. The change in heating distribution during the course of the strengthening phases (not shown) is much less significant with no secondary heating maxima appearing, although there is a tendency for the diabatic heating within the eyewall to become a bit stronger during the course of a strengthening phase.

The effect of eddy diabatic heating was also investigated. These results are not shown since the azimuthally averaged eddy heating was small, typically an order of magnitude smaller than the mean heating terms which is similar to the results of, for instance, Montgomery and Smith (2018). The eddy terms had the largest contribution just below the freezing level and had a dipole-like structure with heating below and cooling above. No significant differences in the azimuthally averaged eddy heating distribution were detected between the strengthening and weakening phases with eddy momentum effects from the VHT-like structures playing a much more significant role in causing the intensity fluctuations than their effect on azimuthally averaged eddy diabatic heating.

In terms of how the heating distribution changes just prior to a weakening phase Fig. 12b,c shows a secondary heating maxima at around $55 \mathrm{~km}$ radius and $5 \mathrm{~km}$ height associated with the inner rainbands. Along these rainbands near their intersection with the eyewall there are regions of enhanced convection which can be seen in Fig. 13a T+44.5 h in the northwest and southeast associated with VHT-like structures which are responsible for most of the heating. The secondary heating maxima associated with the inner rainbands becomes more distinct by $\mathrm{T}+45.5 \mathrm{~h}$ (Fig. 12b) which develops into a secondary updraft by $\mathrm{T}+46.5 \mathrm{~h}$ (Fig. 12c). A single VHT-like structure is still visible at $\mathrm{T}+46.5 \mathrm{~h}$ in the southeast quadrant (Fig. 13c). However, by $\mathrm{T}+47.5 \mathrm{~h}$ (Fig. 13d) an azimuthal symmetrisation has taken place with the inner-rainband convection visible as a second ring outside the eyewall. The heating from VHT-like structures that occur in the inner rainbands near where they intersect with the eyewall becomes less significant between $\mathrm{T}+44.5 \mathrm{~h}$ and $\mathrm{T}+47.5 \mathrm{~h}$ (Fig. 12a-d), but the secondary heating maximum from the inner rainbands becomes more distinct (Fig. 13a-d).

Over the next few hours the secondary convective ring becomes more symmetrical and the VHT-like structures continue to become less visible. Eventually by $\mathrm{T}+50.5 \mathrm{~h}$ the secondary convective ring has replaced the first (Fig. $13 \mathrm{~g}$ ). In the remaining hour of W1 the RMW expands out to coincide with the diabatic heating maximum. Note, the inner rainband activity and the associated VHT-like structures may be necessary conditions for a weakening phase to begin; however, it is not sufficient. For example, prior to $\mathrm{W} 1 \mathrm{a}$ VRW event at $\mathrm{T}+38 \mathrm{~h}$ led to the development of a secondary convective ring, which subsequently weakened and did not replace the primary ring. Another particularly strong single VHT-like event that occurred around T+35, in the eyewall region, also did not lead to an intensity fluctuation. 
It was found that weakening phases were associated with weaker heating outside of the RMW compared to strengthening phases associated with stronger narrower columns of diabatic heating just inside the RMW which is consistent with a simple balanced dynamical interpretation (e.g. Smith and Montgomery, 2016) whereby convection occurring outside the RMW acts to spin-up the primary circulation outside the RMW and spin-down the primary circulation inside the RMW. The cause of the increase in convection outside the RMW was found to be related to VHT-like structures within inner rainbands which de-localized to form a symmetric diabatic heating column outside of the RMW and proceeded to become dominant over the original heating column over a period of a few hours.

\subsection{Unbalanced dynamics and the boundary layer}

If the boundary layer plays a significant role in the cause of the intensity fluctuations then it may be necessary to attempt to understand the fluctuations in terms of the boundary layer spin-up mechanism as described by Montgomery and Smith (2018). This requires air parcels within the boundary layer to gain more AAM through rapid reduction of radial distance than is lost through friction. A consequence of this is the initially subgradient tangential wind within the boundary layer becoming supergradient. Examining the agradient wind in and above the boundary layer allows the importance of the unbalanced spin-up mechanism in the intensity fluctuations to be determined.

\subsubsection{Primary and secondary circulation in or just above the boundary layer}

The agradient wind is the deviation of the tangential wind from gradient wind balance (as in, for example, Miyamoto et al., 2014). The gradient wind is not output directly from the MetUM but calculated from other diagnostic variables. Details of the form of the agradient wind are available in the Appendix.

Figure 14 shows how the agradient wind, the tangential and radial wind vary throughout the simulation both at the radius of $35 \mathrm{~km}$ and at the RMW (such that the agradient wind can be examined both at the eyewall and at a fixed radius as during a weakening phase the RMW increases). A negative agradient wind corresponds to a subgradient flow while a positive agradient wind corresponds to a supergradient flow. The blue curve near the surface is chosen to show the subgradient boundary layer flow. The green curve shows the agradient flow a little higher up but still within the boundary layer (Fig.14a) this is at a height where during the weakening phases the subgradient flow becomes supergradient indicated by the crossing of the zero line). The yellow curve is at a height that roughly corresponds to the middle of the outflow jet and the red curve represents a level near the top of the outflow jet where the flow has returned to near gradient wind balance.

Just prior to the weakening phase the inflow in the boundary layer at a radius of $35 \mathrm{~km}$ decreases (Fig. 14d) while the inflow at larger radii (e.g. $100 \mathrm{~km}$ ) may increase (not shown). This decrease in inflow at small radii is followed by a marked increase in the agradient wind at all levels (Fig. 14a,c). The increase in the agradient wind is not accompanied by an increase in the tangential wind (Fig. 14b) at any level which implies the increase in the agradient wind is caused by a decrease in the pressure gradient force per unit mass (PGF) which is also shown in Fig. $14 \mathrm{a}$ and c. The decrease in the PGF is caused by the appearance of a convergence zone above the boundary layer where balanced inflow, enhanced by rainband convection, meets with the boundary layer outflow jet. The presence of rainband convection may also be responsible for the reduction of the inflow in the 
boundary layer prior to the weakening phase in the eyewall (Fig. 14d) which also explains why the boundary layer tangential wind (Fig. 14b, green curve) stops increasing before the tangential wind stops increasing at higher levels (Fig. 14b, red curve). The reduction in inflow, however, is not enough to spin-down the boundary layer nor prevent the boundary layer winds from becoming more agradient. Therefore, at the surface, the reduction in maximum total winds (black line in Fig. 4) during the weakening phases are not due to a tangential wind decrease in the boundary layer but rather a combination of a decrease in the radial inflow and an azimuthal symmetrisation of the wind field (i.e. the maximum surface wind speed decreases faster than the mean (azimuthally averaged) surface wind speed).

During the weakening phase an increase in the agradient wind is seen within the boundary layer (Fig. $14 \mathrm{a}$ and c) which gives rise to a stronger outflow jet just above the boundary layer (Fig. 14d). This enhanced outflow jet continues to increase throughout the weakening phase and reaches a maximum at the start of the next strengthening phase.

The start of a strengthening phase is characterised by a strong outflow jet and a slightly subgradient 'overshoot' (red line in Fig. 14a slightly below zero near the start of the strengthening phases) i.e. as the ascending air within the super-gradient layer decelerates it overshoots to a value lower than the gradient wind.

\subsubsection{Tangential wind budgets}

To understand how the boundary layer and outflow jet change and lead to a spin-down above the boundary layer Fig. 15 shows how the primary and secondary circulation change and what drives these changes by using the tangential wind budget. The times shown correspond to the times in Fig. 5a-c.

The increase of the agradient wind at the start of the weakening phase leading to an intensification of the outflow jet can be seen by comparing Fig. 15a with Fig. 15c. The main result of this comparison is a radial advection of low angular momentum (Fig. 15d) which acts to cause a spin-down of the eyewall above the boundary layer (Fig. 15c). The spin-down of the tangential wind just above the boundary layer pushes the RMW outwards and results in the 'kink'-like appearance of the RMW. Above the kink the tangential wind is in approximate gradient balance and the flow runs nearly parallel to the AAM surfaces. Eventually the expansion of the RMW above the boundary layer in combination with the weakening inflow within the boundary layer leads to the vertical advection of angular momentum into the low angular momentum region above the boundary layer which can be seen in the pink area near the RMW (in the highlighted yellow ellipse) in Fig. 15f compared to Fig. 15d where the same region is blue. At the increased radius, the coherent eyewall structure reforms with a spin-up as a result of the vertical advection of absolute angular momentum. The outflow jet, which previously reduced the tangential wind in the eyewall now does so within the eye which brings the TC into a strengthening phase. The PGF increases, the supergradient wind in the boundary layer becomes less supergradient, and the outflow jet weakens.

In summary the intensity fluctuations in Hurricane Irma can be understood in terms of unbalanced boundary layer dynamics. Firstly the agradient wind in the boundary layer increases as a result of a decline of the PGF (likely due to an inner rainband creating a convergence zone above the boundary layer), the rapid increase in the supergradient wind within the boundary layer leads to an intensification of the outflow jet just above the boundary layer which acts to spin down the primary circulation above the boundary layer by advecting in low angular momentum air from the eye, as well as expanding the RMW above 
the boundary layer. The eyewall restrengthens above the boundary layer with a higher RMW and a recoupling of the primary circulation at the higher RMW with the boundary layer signals the start of the new strengthening phase. This can be seen explicitly by looking at Fig.12h; the eye-wall forms at approximately the same radius as the updraft located further from the centre of the storm in Fig.12d.

\subsection{Discussion}

During the weakening phases the RMW expanded, the wind speed decreased and the MSLP stagnated or rose, while during the strengthening phases the opposite occurred. These phases were found to be associated with different diabatic heating distributions, with weakening phases associated with broad and weak columns of heating outside the RMW and strengthening phases associated with stronger, narrower heating columns just inside the RMW. The changing diabatic heating structure during the weakening and strengthening phases is consistent with a simple balanced interpretation of the results; however, heating in high inertial stability environments as in Schubert and Hack (1982) was not found to be a useful predictor of the fluctuations, although inertial stability in the core region did overall increase throughout rapid intensification.

The fluctuations observed in Hurricane Irma are proposed to be the result of changes in both the barotropic and convective structure of the storm which is similar to Hankinson et al. (2014) where both convective and barotropic effects caused vacillation cycles in Hurricane Katrina (2005). The start of a weakening phase during a rapid intensification period seems to be triggered by the presence of inner rainband activity, often associated with VHT-like structures, outside of the eyewall that produce significant heating and create a secondary updraft outside of the eyewall (Fig. 18a,d). However, unlike in the case of an eyewall replacement cycle in Judt and Chen (2010) the rainbands are not associated with the convective generation of PV outside the eyewall, but some PV is transported into the eye instead. We have been able to extend the work of Hankinson et al. (2014), using Lagrangian tracers, by showing that PV increases within the centre of the eye were caused by upward and inward advection of PV from the outer eye region. In contrast to Hankinson et al. (2014) this increase of PV in the eye was not associated with a pressure drop.

The effect of the secondary heating maximum is to create a balanced secondary circulation above the boundary layer which, in turn, produces a region of convergence just above the boundary layer radially outward from the outflow jet and lowers the PGF within the boundary layer. The reduced PGF results in an increased supergradient flow within the boundary layer which in turn is ventilated by an increased boundary layer outflow jet. The unbalanced spin-up mechanism as described by Smith et al. (2009) allows the wind to become supergradient within the boundary layer. The boundary layer outflow jet causes further weakening by advecting low angular momentum outwards from the eye and increasing the RMW while spinning down the flow above the boundary layer. Without a coherent heating tower the PV structure tends towards a monopole-like state with high PV from the boundary layer transported into the eye (Fig. 18e). This could be associated with barotropic instability causing a breakdown of the ring-like PV structure (e.g. Kuo et al., 1999; Williams, 2017).

During the weakening phase the VHT-like structures are less favoured to form which results in a more azimuthally symmetric structure (Fig. 18b). When the eyewall reforms at a greater radial distance this symmetric structure is initially maintained (Fig. 18c). However, during the strengthening phase the development of these VHT-like structures becomes increasingly favourable 
https://doi.org/10.5194/wcd-2021-81

Preprint. Discussion started: 3 January 2022

(c) Author(s) 2022. CC BY 4.0 License.

(c) (i)

Weather and

Climate Dynamics

Discussions

(Fig. 18a). Most of the time these VHT-like structures are not harmful to the storm's intensification and can, through the eddy transfer of AAM, contribute to intensification. VHT-like structures that move too far inwards can have a disruptive effect and trigger a weakening phase by decelerating the tangential wind within the eyewall and accelerating it within the eye. These results seem surprising given that Kilroy and Smith (2016) suggest that an updraft in a vortex results in an increased contribution to the tangential wind budget radially outwards of the updraft and a negative contribution radially inwards of the updraft (with more pronounced effects from updraughts further from the storm centre). Some of these VHT-like structures may be related to the vortex Rossby wave activity which occured concurrently in some cases. VHTs often appear in a tropical cyclone's immature phase just prior to rapid intensification, such as in Guimond et al. (2010), where their appearance precedes the rapid strengthening and increased azimuthal symmetry of the storm. Although the VHT-like structures in Hurricane Irma do precede a more azimuthally symmetric state of the storm, this is typically during a weakening phase. This difference, on the storm's intensification, between the impact of VHT-like structures in this study and pre-RI such as in Guimond et al. (2010) suggests that VHT-like structures may have different impacts on a mature storm undergoing rapid intensification compared to a much weaker storm that has not yet undergone rapid intensification.

In a study on vacillation cycles Nguyen et al. (2011) described VHT-like structures that appeared to be the result of barotropic and convective instabilities. The VHT-like structures, in Hurricane Irma here, precede the weakening phase and thus seem to be a cause of the instability rather than a symptom of it. Additionally, the mixing of PV described in Nguyen et al. (2011) causes a decrease in MSLP. However, the opposite of this occurs in the weakening phases in our simulations with MSLP increasing or stagnating during weakening phases. Another key difference between prior work on vacillation cycles is the association of azimuthal symmetry with the radial structure. In Nguyen et al. (2011) the azimuthal symmetry is positively correlated with the ring-like PV distribution, whereas here we have found it to be anti-correlated. The reasons for this are uncertain and should be investigated in future work but it may indicate the fluctuations modelled here may be different kinds of intensity fluctuations to those found in Nguyen et al. (2011).

In terms of trying to understand what these fluctuations are, there are similarities to vacillation cycles particularly with the simulation conducted in Reif et al. (2014) which exhibits transitions from ring-like to monopolar PV distributions but with a more ring-like state than Nguyen et al. (2011). Although one significant difference compared to the vacillation cycles in Hardy et al. (2021) is that the more monopolar state during the weakening phases were transient with $\mathrm{PV}_{0} / \mathrm{PV}_{\text {max }}$ peaking at the end of the weakening phase before dropping rapidly. The role of barotropic and convective instability does also seem to play a role. However, the azimuthally asymmetric VHT-dominated periods (for example in Nguyen et al., 2011) are not explicitly linked to strengthening phases as they are in this study. Fischer et al. (2020) did identify these fluctuations in the observational data of Hurricane Irma and described them as two separate eyewall replacement cycles triggered by lowertropospheric convergence associated with a rainband and lower-tropospheric convergence associated with a super-gradient flow respectively. The fluctuations modelled here have some similarities with the second mechanism proposed in Fischer et al. (2020) with the secondary eyewall merging with the primary eyewall before dissipating. The intensity fluctuations in Irma also have some similarities to a 'partial eyewall replacement cycle' described in Zhang et al. (2017) where the boundary layer updraft is unable to properly couple with a potential secondary updraft above. It is proposed that the fluctuations here are the 
https://doi.org/10.5194/wcd-2021-81

Preprint. Discussion started: 3 January 2022

(c) Author(s) 2022. CC BY 4.0 License.

(c) (i)

Weather and

Climate Dynamics

Discussions

result of the eyewall being temporarily disrupted by VHT-like structures in the inner rainbands and the resultant disruption of the coupling between the boundary layer and the free troposphere and the eventual reformation of the coherent eyewall structure. Unlike an eyewall replacement cycle there is no clear secondary eyewall formation event.

\section{Composites over multiple ensemble forecasts}

The prior analysis has been carried out for one ensemble forecast. To demonstrate the robustness of the analysis composites of selected key results will be presented across multiple ensemble members. Five out of 18 ensemble members (including ensemble member 15), initialized on 03 September 00 UTC, showed the intensity fluctuations previously discussed. A further six ensembles also showed similar but weaker fluctuations. An additional model simulation, initialized on 02 September 12 UTC, found seven out of 18 ensemble members with the same kind of fluctuations. The following composites are based on the five ensemble members initialised on the 03 September at 00 UTC that show the strongest fluctuations. The composites are over all weakening and strengthening phases in all of these five ensemble forecasts. These weakening and strengthening phases vary in length from one hour to 10 hours, with $4-5$ hours being typical and with the data outputted hourly. There are a total of 45 weakening and strengthening phases averaged over.

One of the key aspects of the analysis is the transition during weakening phases from a ring-like PV distribution at the start of the weakening phase towards a more monopolar PV distribution towards the end of the weakening phase. Figure 16 shows a PV tendency composite plot for all weakening and strengthening phases for the five ensemble members with the strongest intensity fluctuations. During the weakening phases there is a positive PV tendency within the inner eye and a negative tendency within the high PV annulus confirming the results from Section 4.2 for Irma's PV structure to become more monopolar in the weakening phases. The opposite is shown in the strengthening phases with PV decreasing in the inner eye and rising in the high PV annulus. Near the RMW outside the PV ring there are positive PV tendencies at the end of the weakening phases which can also be seen in Fig. 5e,j,o,t to Fig. 5d,i,n,s which show, from left to right, the structural PV changes that occur from the start of the weakening phases to the start of the strengthening phases in ensemble member 15. Near the RMW (dashed black line), PV starts to increase at the end of the weakening phases and at the start of the next strengthening phase.

Figure 17 shows the contributions to the tangential wind budget through mean and eddy advection of angular momentum of the strengthening composite relative to the weakening composite (strengthening phases minus weakening phases). Above the boundary layer at a radial distance of $20 \mathrm{~km}$ to $35 \mathrm{~km}$ the eddy term plays a beneficial role in both the strengthening and weakening phases; however, in the strengthening phases the effect is distinctly greater. This comparison confirms some of the findings shown in Fig. 10 that the eddy momentum flux acts to cause intensification above the boundary layer particularly during strengthening phases. The effect of the mean momentum fluxes are also similar with greater tangential wind spin-up in the boundary layer in strengthening phases compared to weakening phases but also with greater spin-down above the boundary layer in the outflow jet during the strengthening phases.

The composites demonstrate that similar processes are likely occurring in the other ensemble members. The fluctuations in intensity that occurred during rapid intensification and are not just limited to a single ensemble member. This study focuses on 
a single case, Hurricane Irma (2017), so it is unclear how common this type of intensity fluctuations is in tropical cyclones. The ensemble forecasts showed no link between the likelihood of the intensity fluctuations and the environmental conditions so the causes of the fluctuations are likely stochastic in nature (in particular with respect to the radial location of VHT-like convective structures that develop). The fluctuations are shown to occur in around a third of the ensemble forecasts suggesting they may be a common feature in rapid intensification and motivating analysis of more cases.

\section{Summary and Conclusions}

The main aim of this study was to determine the cause of the observed intensity fluctuations in Hurricane Irma (2017), during rapid intensification, and to identify the processes responsible. Understanding these fluctuations is important as they can affect both the intensity and size of the RMW in the short term and therefore the destructive potential of the TC. Key and novel results include the finding that intensity fluctuations are related to convective and barotropic structural changes with the asymmetric convection playing a key role in the fluctuations. Both unbalanced and balanced intensification processes were important with the balanced effect of inner rainband convection leading to an unbalanced boundary layer response which, in turn, caused a spin-down during weakening phases. Key findings from this analysis include the following:

- In Hurricane Irma, during the second period of rapid intensification, intensity fluctuations occurred, which caused short term intensification and weakening periods, although overall the storm continued to intensify.

- During strengthening phases the PV distribution was an elongated ring which became more azimuthally symmetric and monopole-like during weakening phases. Note that the azimuthal symmetry is independent of the radial PV distribution and the ring-like PV states (strengthening phases) were associated with less azimuthally symmetric distributions.

- During strengthening phases, the diabatic heating distribution had a smaller radial extent and a stronger heating maximum which is located within the RMW. During weakening phases the heating was outside the RMW and had a greater radial extent than the diabatic heating during the strengthening phases.

- VHT-like structures were stronger and more common during strengthening phases than weakening phases and contributed positively to intensification through eddy advection of angular momentum.

- Unbalanced dynamics were shown to play a role in the intensity fluctuations. During the weakening phases an unbalanced supergradient tangential flow produced an outflow jet which acted to spin-down the flow above the boundary layer by transferring low angular momentum from the eye outwards.

In conclusion, the findings from this analysis, as summarized in Fig. 18, show the proposed mechanism for the intensity fluctuations observed in Hurricane Irma, and highlight the importance of both the VHT-like structures that develop on the intersection of inner rainbands with the eye-wall and of the development of the supergradient wind within the boundary layer. It was found that these intensity fluctuations appear in about $1 / 3$ of the ensemble simulations. No link was found between the 
environment of the storms and the presence of these intensity fluctuations indicating they are governed by stochastic processes. In addition, the intensity of the storms at the end of the simulations with intensity fluctuations were similar to those without, indicating that the increased intensification rates during strengthening phases compensated for the weakening phases. This study gives potentially further insight into intensity fluctuations during rapid intensification, such as the vacillation cycles in Nguyen et al. (2011), and emphasises the role of the inner rainbands in causing weakening periods. It also offers an explanation for the observed intensity fluctuations in Hurricane Irma observed in Fischer et al. (2020). A future direction of this work would be to investigate the similarities between these fluctuations in rapid intensification and eyewall replacement cycles and whether they are caused by similar processes and to analyse more cases to assess to what extent these results can be generalized.

Data availability. Observational data used in this paper is made available online by the Hurricane Research Division and is available at https://www.aoml.noaa.gov/hrd/Storm_pages/irma2017/. The microwave data is made available online by CIMSS at http://tropic.ssec.wisc. edu/real-time/mimtc/2017_11L/web/mainpage.html. The model fields in a 200km box around the storm which are used for the analysis in this paper have been stored and can be made available on request.

\section{Appendix A: Calculation of agradient wind}

665 The agradient wind is determined by taking the gradient wind balance, where the pressure force is balanced by the sum of the Coriolis and centrifugal forces: $\frac{1}{\rho} \frac{\partial p}{\partial r}=\frac{v_{g}^{2}}{r}+f r$, where $\rho$ is the dry density, $p$ the pressure, $v_{g}$ is the gradient wind, $f$ the Coriolis parameter and $r$ the radial distance from the centre. Substituting in the ideal gas law: $\mathrm{p}=\rho \mathrm{RT}$, where $R$ the ideal gas constant and $T$ the temperature, and then noting that the agradient wind is given by the deviation of the tangential wind from the balanced tangential wind: $\mathrm{v}_{\mathrm{ag}}=\mathrm{v}-\mathrm{v}_{\mathrm{g}}$ where $v_{a g}$ is the agradient wind we arrive at,

$670 v_{a g}=v-\frac{1}{2}\left(\sqrt{\frac{4 R r T}{p} \frac{\partial p}{\partial r}+f^{2} r^{2}}-f r\right)$.

Physically the agradient wind represents the deviation of the primary circulation from gradient wind balance. A subgradient wind means the wind speed is lower than the gradient wind, while a supergradient wind is higher than the gradient wind. In the boundary layer, both subgradient and supergradient winds are often found. At the surface friction reduces the tangential wind and causes it to be subgradient but the frictionally induced inflow can also lead to tangential acceleration at higher levels and smaller radii which sometimes results in a supergradient layer.

Author contributions. William Torgerson: Conceptualization, Formal Analysis, Investigation, Methodology, Software, Writing - Original Draft Preparation. Juliane Schwendike: Conceptualization, Supervision, Writing - Review and Editing. Andrew Ross: Conceptualization, Supervision, Writing - Review and Editing. Chris Short: Data Curation, Methodology, Supervision, Writing - Review and Editing. 
https://doi.org/10.5194/wcd-2021-81

Preprint. Discussion started: 3 January 2022

(C) Author(s) 2022. CC BY 4.0 License.

(c) (i)

Weather and

Climate Dynamics

Discussions

Competing interests. There are no competing interests

680 Acknowledgements. We thank the Hurricane Research Division for providing dropsonde and flight-level data as well as the images contained in Fig. 3a-d (available online at https://www.aoml.noaa.gov/hrd/). We thank the Cooperative Institute for Meterological Satellite Studies for making the microwave imagery available contained in Fig. 3e-f (available online at http://tropic.ssec.wisc.edu/real-time/mimtc/2017_11L/ web/mainpage.html). This work used MONSooN2 (the Met Office and NERC supercomputing node) a collaborative high-performance computing facility funded by the Met Office and the Natural Environment Research Council. Torgerson was funded by a PhD scholarship from the NERC SPHERES DTP (grant NE/L002574/1) and CASE support from the Met Office. 
https://doi.org/10.5194/wcd-2021-81

Preprint. Discussion started: 3 January 2022

(C) Author(s) 2022. CC BY 4.0 License.
Weather and

Climate Dynamics

Discussions

\section{References}

Arakawa and Lamb: "Computational design of the basic dynamical processes of the ucla general circulation model,", in: General Circulation Models of the Atmosphere, edited by CHANG, J., vol. 17 of Methods in Computational Physics: Advances in Research and Applications, pp. 173-265, Elsevier, https://doi.org/https://doi.org/10.1016/B978-0-12-460817-7.50009-4, 1977.

Bell, M. M. and Lee, W.-C.: “Objective tropical cyclone center tracking using single-doppler radar,", Journal of Applied Meteorology and Climatology, 51, 878 - 896, https://doi.org/10.1175/JAMC-D-11-0167.1, 2012.

Best, M. J.: "The joint UK land environment simulator (JULES), model description-Part 1: Energy and water fluxes,", Geoscientific Model Development, 4, 595-640, 2011.

Bishop, C. H., Etherton, B. J., and Majumdar, S. J.: "Adaptive sampling with the ensemble transform Kalman filter. Part I: Theoretical aspects,", Monthly Weather Review, 129, 420 - 436, https://doi.org/10.1175/1520-0493(2001)129<0420:ASWTET>2.0.CO;2, 2001.

Black, P. G., D’Asaro, E. A., Drennan, W. M., French, J. R., Niiler, P. P., Sanford, T. B., Terrill, E. J., Walsh, E. J., and Zhang, J. A.: “Air sea exchange in hurricanes: Synthesis of observations from the coupled boundary layer air sea transfer experiment,", Bulletin of the American Meteorological Society, 88, 357 - 374, https://doi.org/10.1175/BAMS-88-3-357, 2007.

Bowler, N. E., Arribas, A., Mylne, K. R., Robertson, K. B., and Beare, S. E.: "The MOGREPS short-range ensemble prediction system,", Quarterly Journal of the Royal Meteorological Society, 134, 703-722, https://doi.org/https://doi.org/10.1002/qj.234, 2008.

Bowler, N. E., Arribas, A., Beare, S. E., Mylne, K. R., and Shutts, G. J.: "The local ETKF and SKEB: Upgrades to the MOGREPS short-range ensemble prediction system,", Quarterly Journal of the Royal Meteorological Society, 135, 767-776, https://doi.org/https://doi.org/10.1002/qj.394, 2009.

Bush, M., Allen, T., Bain, C., Boutle, I., Edwards, J., Finnenkoetter, A., Franklin, C., Hanley, K., Lean, H., Lock, A., Manners, J., Mittermaier, M., Morcrette, C., North, R., Petch, J., Short, C., Vosper, S., Walters, D., Webster, S., Weeks, M., Wilkinson, J., Wood, N., and Zerroukat, M.: “The first Met Office Unified Model-JULES regional atmosphere and land configuration, RAL1,", Geoscientific Model Development, 13, 1999-2029, https://doi.org/10.5194/gmd-13-1999-2020, 2020.

Cangialosi and Berg: "National Hurricane Center tropical cyclone report Hurricane Irma (AL112017) 20 August.,", NOAA, 2018.

Chagnon, J. M., Gray, S. L., and Methven, J.: “Diabatic processes modifying potential vorticity in a North Atlantic cyclone,”, Quarterly Journal of the Royal Meteorological Society, 139, 1270-1282, https://doi.org/https://doi.org/10.1002/qj.2037, 2013.

Charney, J. G. and Phillips, N. A.: "Numerical integration of the quasi-geostrophic equations for barotropic and simple baroclinic flows,", Journal of Atmospheric Sciences, 10, 71 - 99, https://doi.org/10.1175/1520-0469(1953)010<0071:NIOTQG>2.0.CO;2, 1953.

Clark, D. B., Mercado, L. M., Sitch, S., Jones, C. D., Gedney, N., Best, M. J., Pryor, M., Rooney, G. G., Essery, R. L. H., Blyth, E., Boucher, O., Harding, R. J., Huntingford, C., and Cox, P. M.: "The joint UK land environment simulator (JULES), model description - Part 2: Carbon fluxes and vegetation dynamics,", Geoscientific Model Development, 4, 701-722, https://doi.org/10.5194/gmd-4-701-2011, 2011. Cullen, M. J. P.: “The unified forecast/climate model,”, Meteorological Magazine, 122, 81-94, 1993.

DeMaria, M., Franklin, J. L., Onderlinde, M. J., and Kaplan, J.: "Operational forecasting of tropical cyclone rapid intensification at the National Hurricane Center,", Atmosphere, 12, https://doi.org/10.3390/atmos12060683, 2021.

Dunion, J., Thorncroft, C., and Velden, C.: “The tropical cyclone diurnal cycle of mature hurricanes,", Monthly Weather Review, 142, 39003919, https://doi.org/10.1175/MWR-D-13-00191.1, 2014.

Eliassen, A.: "Slow thermally or frictionally controlled meridional circulation in a circular vortex,", Astrophisica Norvegica, 5, 19-60, 1951. 
https://doi.org/10.5194/wcd-2021-81

Preprint. Discussion started: 3 January 2022

(c) Author(s) 2022. CC BY 4.0 License.

(c) $\underset{\mathrm{By}}{\mathrm{P}}$

Weather and

Climate Dynamics

Discussions

Fischer, M. S., Rogers, R. F., and Reasor, P. D.: "The rapid intensification and eyewall replacement cycles of Hurricane Irma (2017),", Monthly Weather Review, 148, 981-1004, https://doi.org/10.1175/MWR-D-19-0185.1, 2020.

Guimond, S. R., Heymsfield, G. M., and Turk, F. J.: "Multiscale observations of Hurricane Dennis (2005): The effects of hot towers on rapid intensification,", Journal of the Atmospheric Sciences, 67, 633-654, https://doi.org/10.1175/2009JAS3119.1, 2010.

Hankinson, M. C. N., Reeder, M. J., Davidson, N. E., and Puri, K.: "Vacillation cycles in simulations of Hurricane Katrina,", Quarterly Journal of the Royal Meteorological Society, 140, 1878-1888, https://doi.org/10.1002/qj.2275, 2014.

Hardy, S., Schwendike, J., Smith, R. K., Short, C. J., Reeder, M. J., and Birch, C. E.: "Fluctuations in inner-core structure during the rapid intensification of super Typhoon Nepartak (2016),", Monthly Weather Review, 149, 221 - 243, https://doi.org/10.1175/MWR-D-190415.1, 2021.

Heming, J. T.: "Met Office Unified Model tropical cyclone performance following major changes to the initialization scheme and a model Upgrade,", Weather and Forecasting, 31, 1433-1449, https://doi.org/10.1175/waf-d-16-0040.1, 2016.

Judt, F. and Chen, S. S.: "Convectively generated potential vorticity in rainbands and formation of the secondary eyewall in Hurricane Rita of 2005,", Journal of the Atmospheric Sciences, 67, 3581 - 3599, https://doi.org/10.1175/2010JAS3471.1, 2010.

Kaplan, J. and DeMaria, M.: "Large-scale characteristics of rapidly intensifying tropical cyclones in the North Atlantic Basin,", Weather and Forecasting, 18, 1093 - 1108, https://doi.org/10.1175/1520-0434(2003)018<1093:LCORIT>2.0.CO;2, 2003.

Kaplan, J., Demaria, M., and Knaff, J. A.: “A revised tropical cyclone rapid intensification index for the Atlantic and Eastern North Pacific basins,", Weather and Forecasting, 25, 220-241, https://doi.org/10.1175/2009waf2222280.1, 2010.

Kilroy, G. and Smith, R. K.: “A numerical study of deep convection in tropical cyclones,", Quarterly Journal of the Royal Meteorological Society, 142, 3138-3151, https://doi.org/https://doi.org/10.1002/qj.2895, 2016.

Kossin, J. P. and Eastin, M. D.: "Two distinct regimes in the kinematic and thermodynamic structure of the hurricane eye and eyewall,", Journal of the Atmospheric Sciences, 58, 1079-1090, https://doi.org/10.1175/1520-0469(2001)058<1079:TDRITK>2.0.CO;2, 2001.

Kuo, H.-C., Williams, R. T., and Chen, J.-H.: “A possible mechanism for the eye rotation of Typhoon Herb,”, Journal of the Atmospheric Sciences, 56, 1659-1673, https://doi.org/10.1175/1520-0469(1999)056<1659:APMFTE>2.0.CO;2, 1999.

Landsea, C. W. and Franklin, J. L.: “Atlantic hurricane database uncertainty and presentation of a new database format,", Monthly Weather Review, 141, 3576-3592, https://doi.org/10.1175/MWR-D-12-00254.1, 2013.

Lee, J.-D., Wu, C.-C., and Ito, K.: "Diurnal variation of the convective area and eye size associated with the rapid intensification of tropical cyclones,", Monthly Weather Review, 148, 4061-4082, https://doi.org/10.1175/MWR-D-19-0345.1, 2020.

Miyamoto, Y., Satoh, M., Tomita, H., Oouchi, K., Yamada, Y., Kodama, C., and Kinter, J.: “Gradient wind balance in tropical cyclones in high-resolution global experiments,", Monthly Weather Review, 142, 1908 - 1926, https://doi.org/10.1175/MWR-D-13-00115.1, 2014.

Montgomery, M. T. and Kallenbach, R. J.: "A theory for vortex Rossby-waves and its application to spiral bands and intensity changes in hurricanes,", Quarterly Journal of the Royal Meteorological Society, 123, 435-465, https://doi.org/10.1002/qj.49712353810, 1997.

Montgomery, M. T. and Smith, R. K.: "Comments on revisiting the balanced and unbalanced aspects of tropical cyclone intensification,", Journal of the Atmospheric Sciences, 75, 2491-2496, https://doi.org/10.1175/JAS-D-17-0323.1, 2018.

Montgomery, M. T., Zhang, J. A., and Smith, R. K.: "An analysis of the observed low-level structure of rapidly intensifying and mature Hurricane Earl (2010),", Quarterly Journal of the Royal Meteorological Society, 140, 2132-2146, https://doi.org/https://doi.org/10.1002/qj.2283, 2014.

Nguyen, M. C., Reeder, M. J., Davidson, N. E., Smith, R. K., and Montgomery, M. T.: "Inner-core vacillation cycles during the intensification of Hurricane Katrina,", Quarterly Journal of the Royal Meteorological Society, 137, 829-844, 2011. 
https://doi.org/10.5194/wcd-2021-81

Preprint. Discussion started: 3 January 2022

(c) Author(s) 2022. CC BY 4.0 License.

(c) (i)

Weather and

Climate Dynamics

Discussions
760

Persing, J., Montgomery, M. T., McWilliams, J. C., and Smith, R. K.: "Asymmetric and axisymmetric dynamics of tropical cyclones,", Atmospheric Chemistry and Physics, 13, 12 299-12 341, https://doi.org/10.5194/acp-13-12299-2013, 2013.

Powell, M. D., Vickery, P. J., and Reinhold, T. A.: "Reduced drag coefficient for high wind speeds in tropical cyclones,", Nature, 422, 279-283, https://doi.org/10.1038/nature01481, 2003.

Prieto, R., Kossin, J. P., and Schubert, W. H.: “Symmetrization of lopsided vorticity monopoles and offset hurricane eyes,”, Quarterly Journal

Reasor, P. D., Rogers, R., and Lorsolo, S.: "Environmental flow impacts on tropical cyclone structure diagnosed from airborne doppler radar composites,”, Monthly Weather Review, 141, 2949-2969, https://doi.org/10.1175/mwr-d-12-00334.1, 2013.

Reif, M., Reeder, M., and Hankinson, C.: "Vacillation cycles in WRF simulations of Hurricane Katrina,", Journal of Southern Hemisphere Earth Systems Science, 64, 123 - 131, 2014.

Riemer, M., Montgomery, M. T., and Nicholls, M. E.: "A new paradigm for intensity modification of tropical cyclones: Thermodynamic impact of vertical wind shear on the inflow layer,", Atmospheric Chemistry and Physics, 10, 3163-3188, https://doi.org/10.5194/acp-103163-2010, 2010.

Ryglicki, D. R. and Hart, R. E.: "An investigation of center-finding techniques for tropical cyclones in mesoscale models,", Journal of Applied Meteorology and Climatology, 54, 825-846, https://doi.org/10.1175/jamc-d-14-0106.1, 2015.

Saffin, L., Methven, J., and Gray, S. L.: "The non-conservation of potential vorticity by a dynamical core compared with the effects of parametrized physical processes,", Quarterly Journal of the Royal Meteorological Society, 142, 1265-1275, https://doi.org/10.1002/qj.2729, 2016.

Schubert, W. H. and Hack, J. J.: "Inertial stability and tropical cyclone development,", Journal of the Atmospheric Sciences, 39, 1687-1697, https://doi.org/10.1175/1520-0469(1982)039<1687:isatcd>2.0.co;2, 1982.

Schubert, W. H., Montgomery, M. T., Taft, R. K., Guinn, T. A., Fulton, S. R., Kossin, J. P., and Edwards, J. P.: "Polygonal eyewalls, asymmetric eye contraction, and potential vorticity mixing in hurricanes,", Journal of the Atmospheric Sciences, 56, 1197 - 1223 , https://doi.org/10.1175/1520-0469(1999)056<1197:PEAECA>2.0.CO;2, 1999.

Short, C. J. and Petch, J.: "How well can the Met Office Unified Model forecast tropical cyclones in the western North Pacific?,", Weather and Forecasting, 33, 185-201, https://doi.org/10.1175/waf-d-17-0069.1, 2018.

Smith, K. C. and Eastin, M. D.: “Composite structure of vortical hot towers in Hurricane Guillermo (1997),", Journal of the Atmospheric Sciences, 2010.

Smith, R. K. and Montgomery, M. T.: “The efficiency of diabatic heating and tropical cyclone intensification.,", Quarterly Journal of the Royal Meteorological Society, 39, 2081-2086, https://doi.org/:10.1002/ qj.2804., 2016.

Smith, R. K., Montgomery, M. T., and Van Sang, N.: “Tropical cyclone spin-up revisited,”, Quarterly Journal of the Royal Meteorological Society, 135, 1321-1335, https://doi.org/https://doi.org/10.1002/qj.428, 2009.

Stern, D. P. and Zhang, F.: "How does the eye warm? Part II: Sensitivity to vertical wind shear and a trajectory analysis,", Journal of the Atmospheric Sciences, 70, 1849-1873, https://doi.org/10.1175/JAS-D-12-0258.1, 2013.

Velden, C. S. and Herndon, D.: “A consensus approach for estimating tropical cyclone intensity from meteorological satellites: SATCON,”, Weather and Forecasting, 35, 1645-1662, https://doi.org/10.1175/WAF-D-20-0015.1, 2020. 3350, https://doi.org/10.1175/2009jas3092.1, 2009. 
https://doi.org/10.5194/wcd-2021-81

Preprint. Discussion started: 3 January 2022

(C) Author(s) 2022. CC BY 4.0 License.
Weather and

Climate Dynamics

Discussions

Walters, D., Boutle, I., Brooks, M., Melvin, T., Stratton, R., Vosper, S., Wells, H., Williams, K., Wood, N., Allen, T., Bushell, A., Copsey, D., Earnshaw, P., Edwards, J., Gross, M., Hardiman, S., Harris, C., Heming, J., Klingaman, N., Levine, R., Manners, J., Martin, G., Milton, S., Mittermaier, M., Morcrette, C., Riddick, T., Roberts, M., Sanchez, C., Selwood, P., Stirling, A., Smith, C., Suri, D., Tennant, W., Vidale, P. L., Wilkinson, J., Willett, M., Woolnough, S., and Xavier, P.: "The Met Office Unified Model Global Atmosphere 6.0/6.1 and JULES global land 6.0/6.1 configurations,", Geoscientific Model Development, 10, 1487-1520, https://doi.org/10.5194/gmd-10-1487-2017, 2017.

Williams, G.: "The generation and maintenance of hollow PV towers in a forced primitive equation model,", Proceedings, 1, 156, https://doi.org/10.3390/ecas2017-04149, 2017.

Willoughby, H. E., Clos, J. A., and Shoreibah, M. G.: "Concentric eye walls, secondary wind maxima, and the evolution of the hurricane vortex,", Journal of Atmospheric Sciences, 39, 395 - 411, https://doi.org/10.1175/1520-0469(1982)039<0395:CEWSWM>2.0.CO;2, 1982.

Wimmers, A. J. and Velden, C. S.: "MIMIC: A new approach to visualizing satellite microwave imagery of tropical cyclones,", Bulletin of the American Meteorological Society, 88, 1187-1196, https://doi.org/10.1175/BAMS-88-8-1187, 2007.

Wood, N., Staniforth, A., White, A., Allen, T., Diamantakis, M., Gross, M., Melvin, T., Smith, C., Vosper, S., Zerroukat, M., and Thuburn, J.: "An inherently mass-conserving semi-implicit semi-lagrangian discretization of the deep-atmosphere global non-hydrostatic equations,", Quarterly Journal of the Royal Meteorological Society, 140, 1505-1520, https://doi.org/https://doi.org/10.1002/qj.2235, 2014.

Yeung, H.: "Convective hot tower signatures and rapid intensification of severe Typhoon Vicente (1208),", Tropical Cyclone Research and Review, 2, 96-108, https://doi.org/https://doi.org/10.6057/2013TCRR02.03, 2013.

Zhang, F., Tao, D., Sun, Y. Q., and Kepert, J. D.: "Dynamics and predictability of secondary eyewall formation in sheared tropical cyclones,", Journal of Advances in Modeling Earth Systems, 9, 89-112, https://doi.org/https://doi.org/10.1002/2016MS000729, 2017. 
(a)

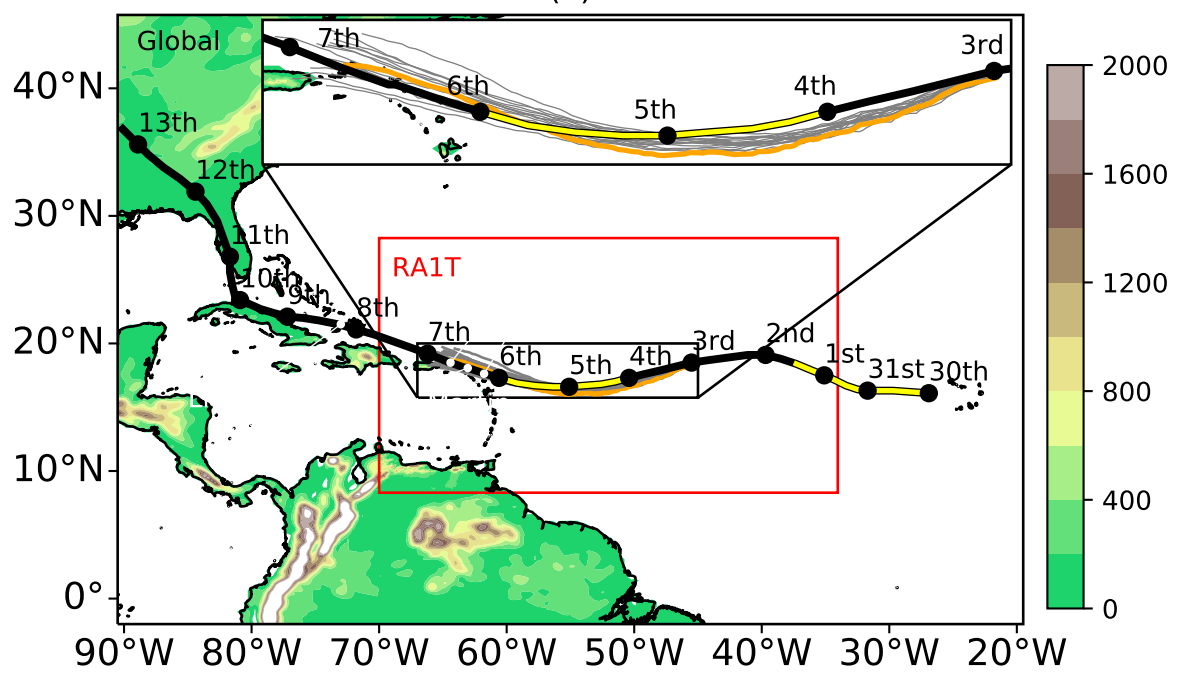

(b)

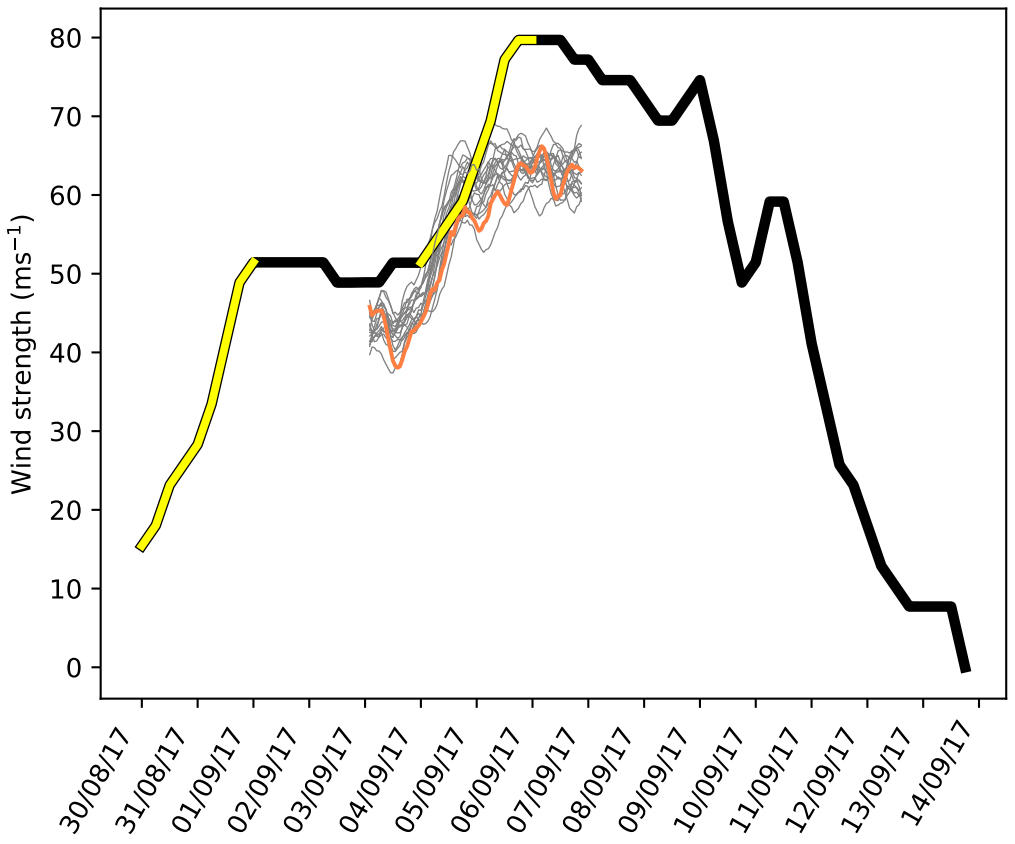

Figure 1. (a) Best track of Hurricane Irma (black line) with points corresponding to the position of Irma on each date from 30 August 2017 to 13 September 2017. Orography (m) is shown in shading. The domain of the regional model used in this study is shown by the red rectangle. The 18-ensemble member tracks are displayed in grey with ensemble member 15 shown in orange. Islands where landfall occurred are indicated by white dots and labels. (b) The best track wind speed (black), the maximun surface wind speed of the ensemble members initialised on 03 September 00 UTC (grey contours) with ensemble member 15 highlighted in orange. In both panels periods of RI are highlighted in yellow. 


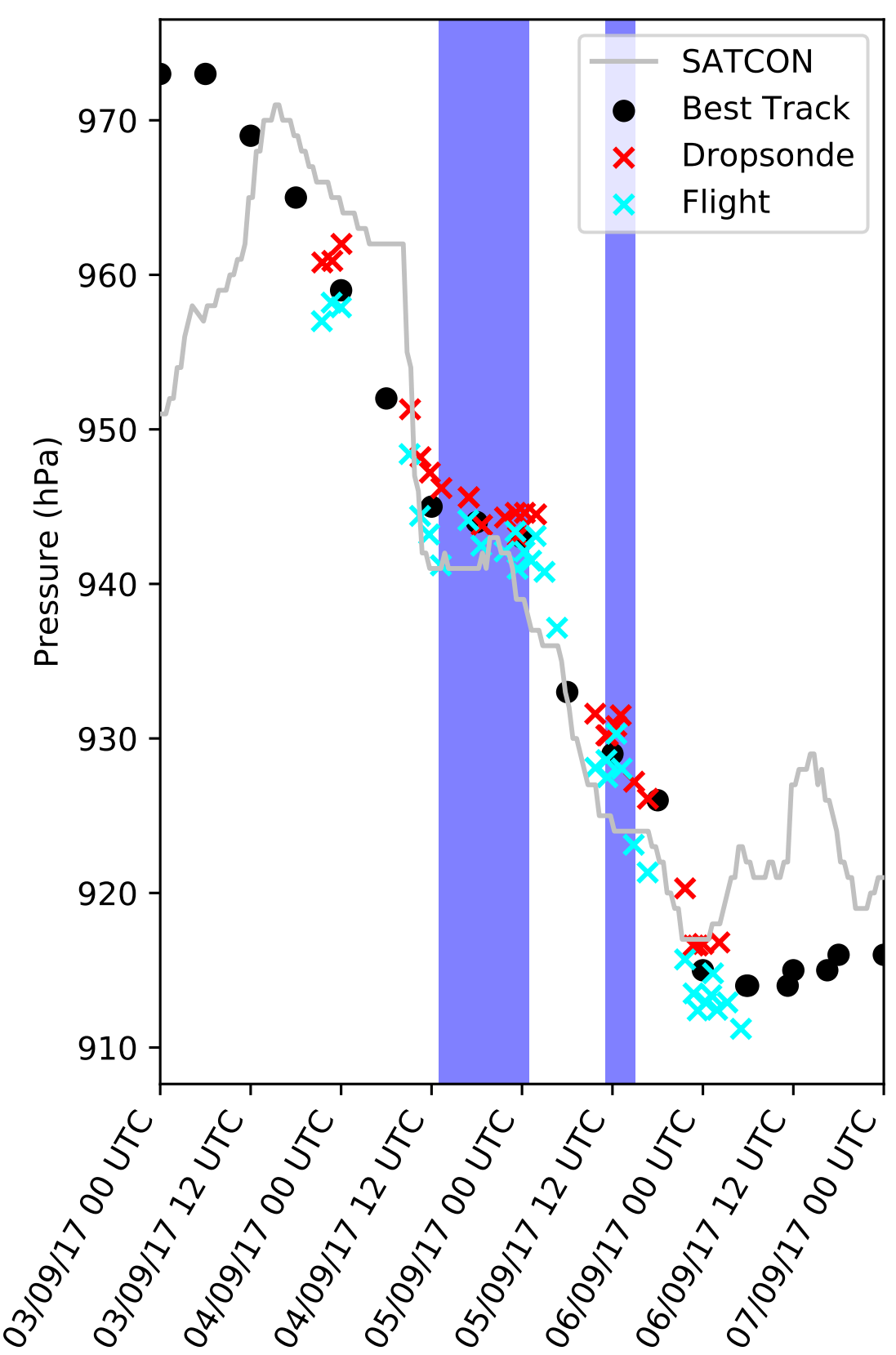

Figure 2. Observed minimum sea level pressure as a function of time based on SATCON and NHC forecaster assessed Best Track estimates as well as direct dropsonde and flight measurements. The 96-hour period shown is the same as the simulation initialized on 03 September 00 UTC. Two notable weakening/stagnation periods during the period of rapid intensification are highlighted by the blue bands. 
https://doi.org/10.5194/wcd-2021-81

Preprint. Discussion started: 3 January 2022

(C) Author(s) 2022. CC BY 4.0 License.
Weather and

Climate Dynamics

Discussions

\section{L...}

(a)

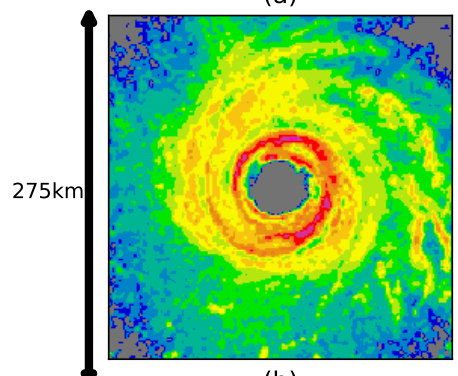

(b)

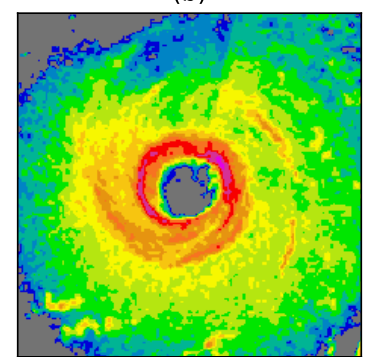

(c)

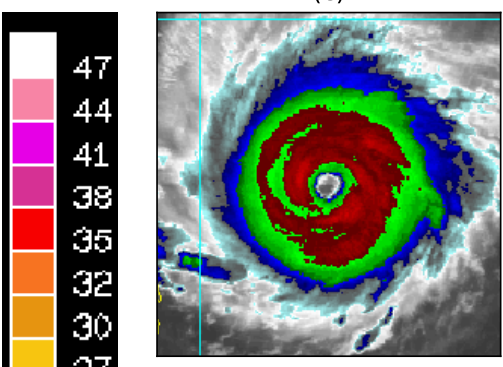

(d)

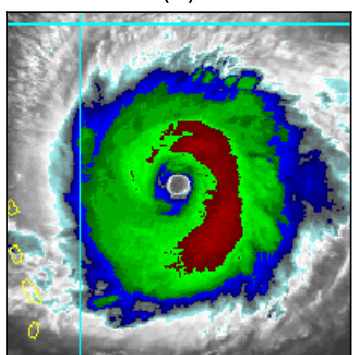

(e)

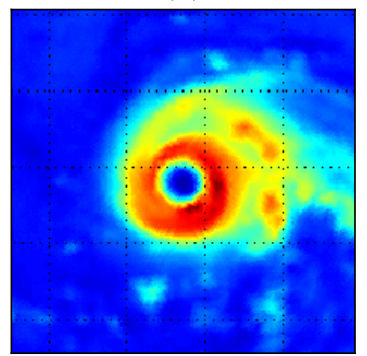

(f)
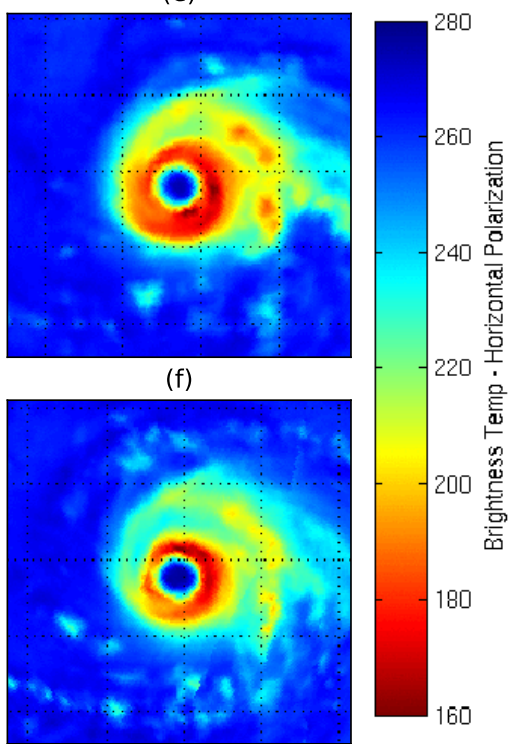

Figure 3. NOAA P3 flight-level radar (in dBZ) on (a) 05 September 0943 UTC and (b) 05 September 1232 UTC, colour enhanced infrared (IR) imagery (in ${ }^{\circ} \mathrm{C}$ ) on (c) 05 September 0945 UTC and (d) 05 September 1245 UTC, and MIMIC microwave imagery (brightness temperature in K) for (e) 05 September 0945 UTC, (f) 05 September 1245 UTC. The upper and lower rows correspond to times just before and after the start of the period indicated by the second blue bar in Fig 2. 


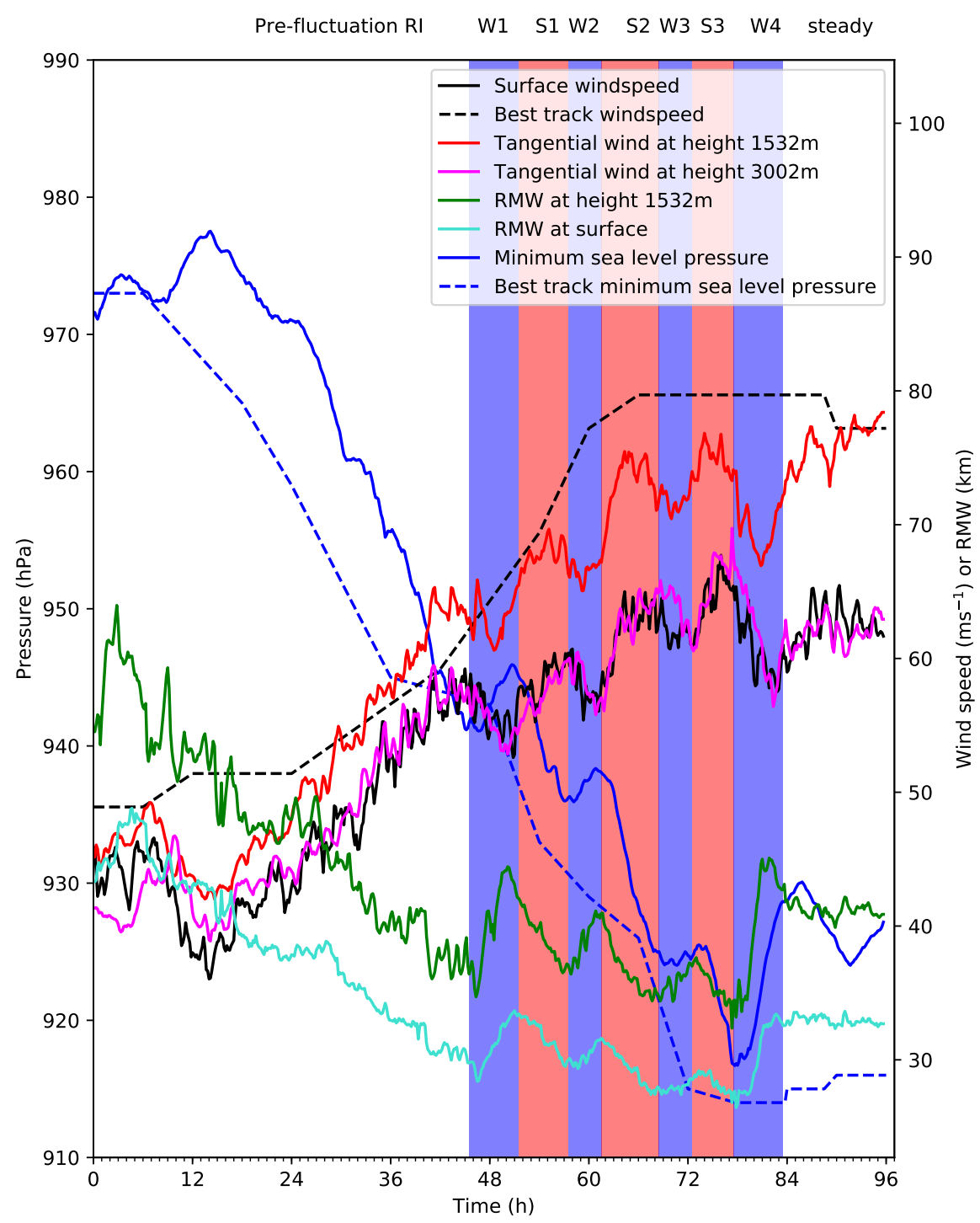

Figure 4. Various model diagnostics (solid lines) and corresponding observations (doted lines, where available) as a function of time. Details are given in the legend. Blue bands indicate weakening phases, and red bands indicate strengthening phases during the rapid intensification period. The individual strengthening and weakening phases have been labelled (see top of plot). W stands for 'weakening', S stands for 'strengthening'. Phases have been subjectively identified. 

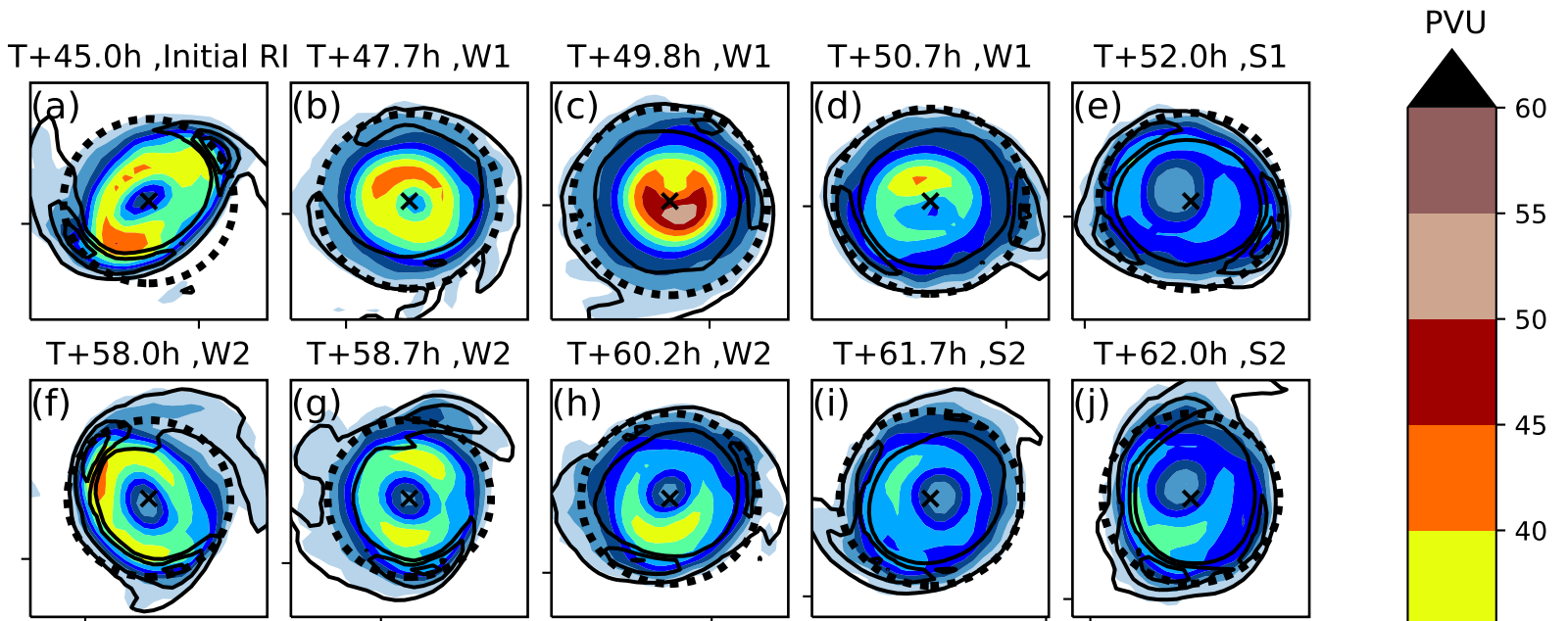

$\mathrm{T}+68.0 \mathrm{~h}, \mathrm{~S} 2$
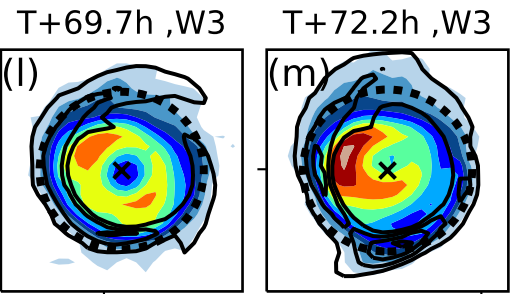

$\mathrm{T}+72.8 \mathrm{~h}, \mathrm{~S} 3$
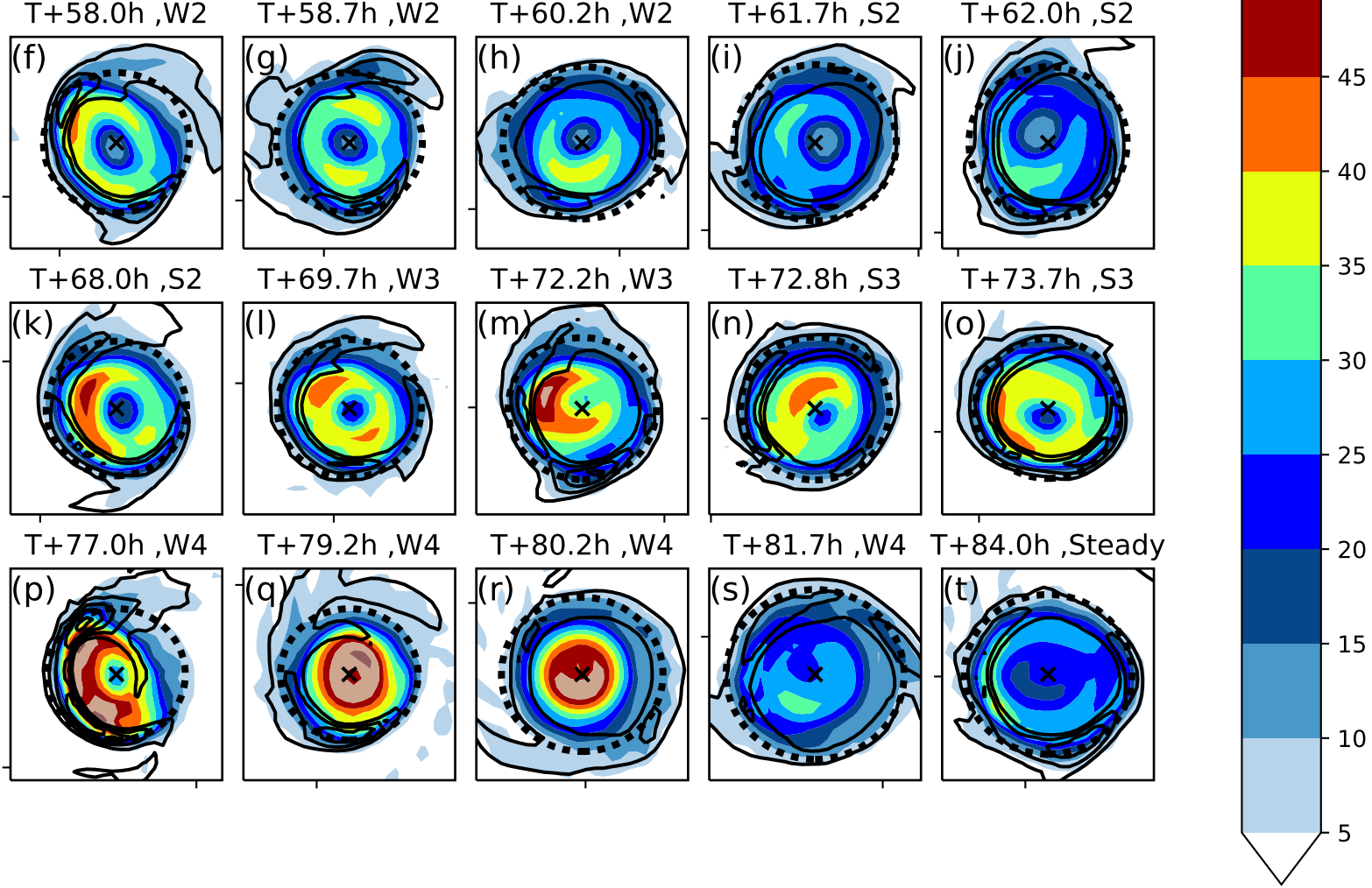

Figure 5. PV (PVU, shaded) at $1532 \mathrm{~m}$ height for selected times and vertical velocity ( $1 \mathrm{~m} \mathrm{~s}^{-1}$, black contour). The RMW is indicated by the dashed black line. A cross marks the centre of the TC. The data is output in 10-minute intervals, times are given to the nearest 0.1 hours. The data is from ensemble member 15 which was initialised at 03 September 2017 at 00 UTC. 

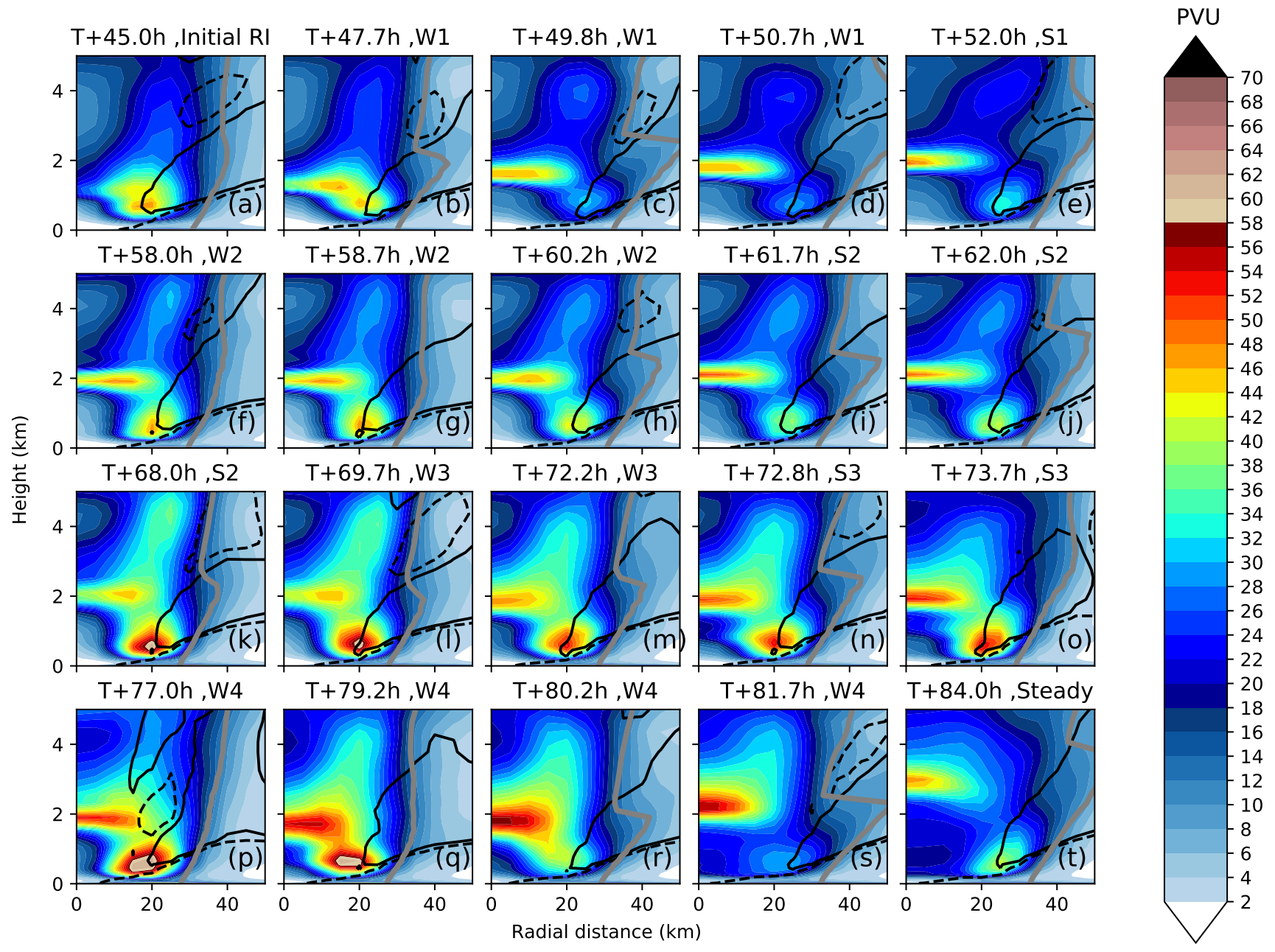

Figure 6. Azimuthally averaged PV (PVU, shaded) as a function of radial distance and height for selected times. The RMW is indicated by the grey line. Also shown are the $1 \mathrm{~m} \mathrm{~s}^{-1}$ (black line) and $-1 \mathrm{~m} \mathrm{~s}^{-1}$ (dashed black line) radial wind contours. 

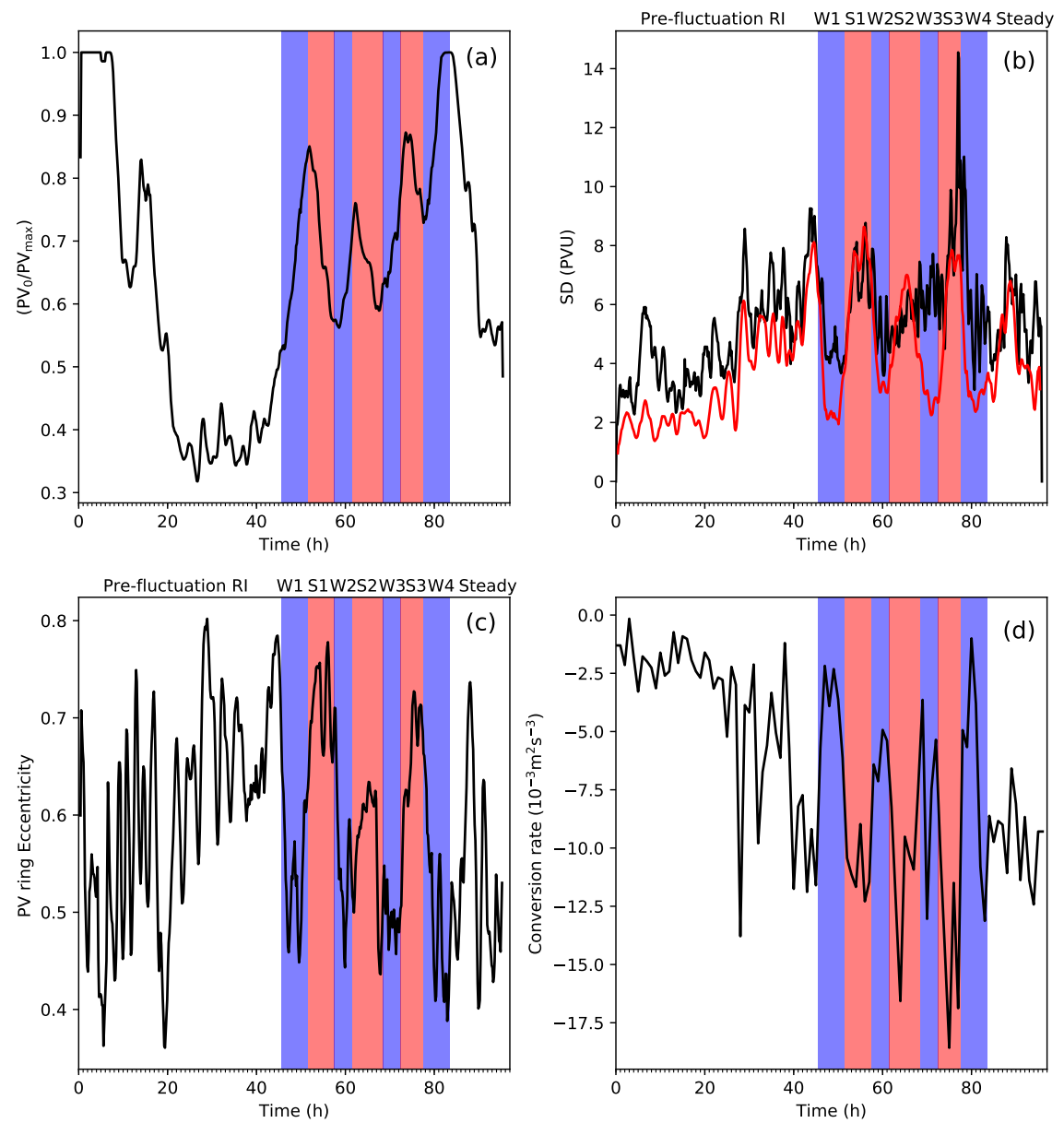

Figure 7. (a) Ratio of the low-level PV (depth averaged between $1052 \mathrm{~m}$ and $4062 \mathrm{~m}$ ) at the centre of the TC to the maximum azimuthally averaged low-0-level PV. (b) Maximum standard deviation of PV at $1532 \mathrm{~m}$ (black) and standard deviation of PV at $1532 \mathrm{~m}$ at the RMW (red). (c) Eccentricity of the ring fitted to the PV distribution at $1532 \mathrm{~m}$. (d) Average barotropic conversion rate from the surface to $4062 \mathrm{~m}$ averaged between $5 \mathrm{~km}$ and $70 \mathrm{~km}$ as a function of time. To smooth out high frequency noise a 1-h running mean is applied to the 10-minute data. Weakening (blue) and strengthening (red) phases are also shown. 
https://doi.org/10.5194/wcd-2021-81

Preprint. Discussion started: 3 January 2022

(c) Author(s) 2022. CC BY 4.0 License.

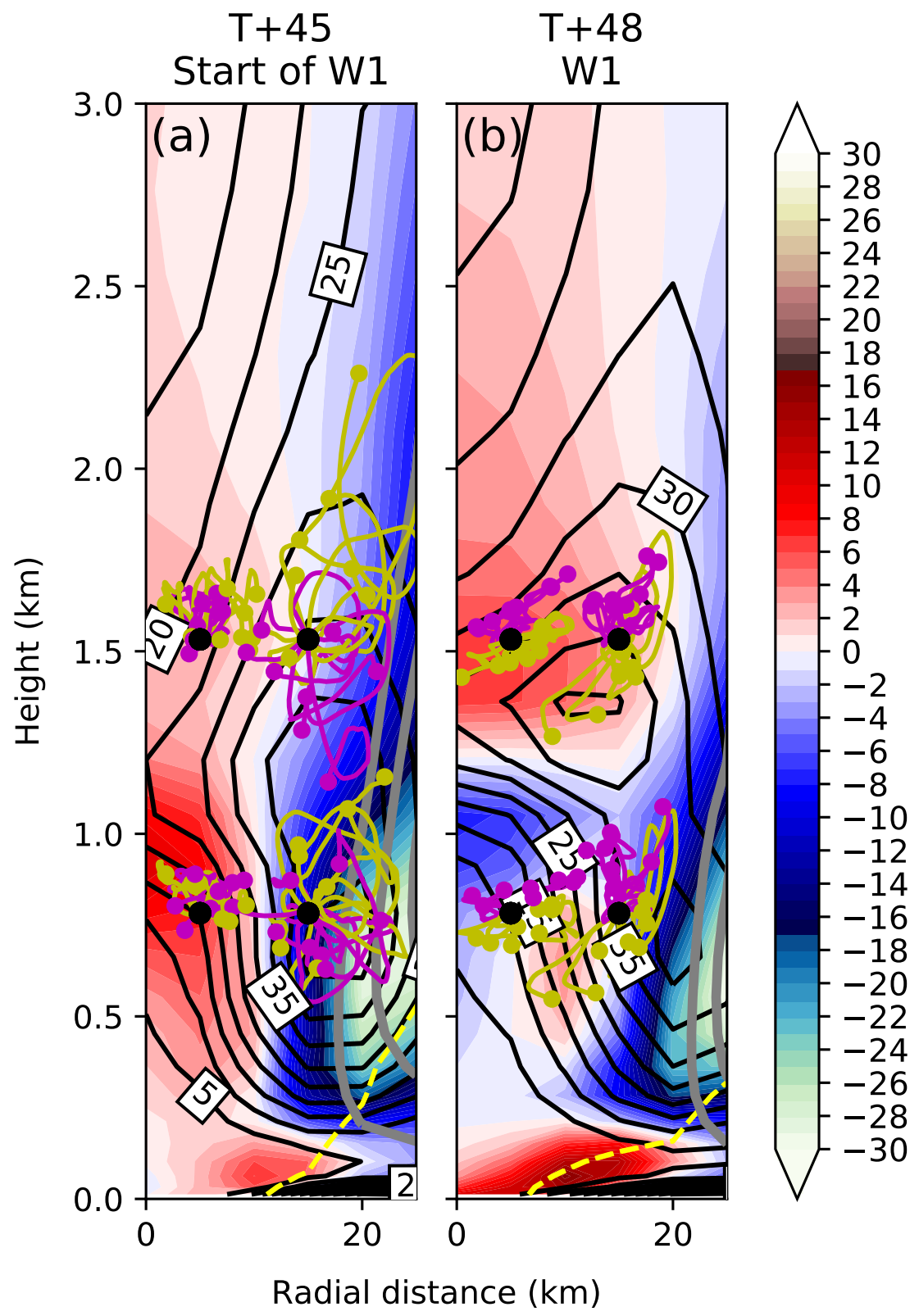

Figure 8. Change in PV over the past hour due to advection only (shaded, $\mathrm{PVUh}^{-1}$ ). Black line contours show the $\mathrm{PV}$ field in intervals of 5 PVU. Additionally, four sets of trajectories are shown for the following (r,z) points (black scatter points): $(5 \mathrm{~km}, 1532 \mathrm{~m}),(15 \mathrm{~km}, 1532 \mathrm{~m})$, $(5 \mathrm{~km}, 782 \mathrm{~m})$, and $(15 \mathrm{~km}, 782 \mathrm{~m})$. Purple lines and scatter points represent the forward trajectory over the next hour while mustard lines and scatter points represent the backward trajectory over the previous hour. Each set of trajectories contains 8 points going back or forward with the same radial distance from the storm centre but with different azimuthal angles around the storm centre: to the east, northeast, north, northwest, west, southwest, south and southeast of the storm centre. The grey contours show vertical velocity (ascent) in $0.25 \mathrm{~m} \mathrm{~s}^{-1}$ intervals indicating the location of the inner eyewall. Yellow dashed line shows the $-1 \mathrm{~m} \mathrm{~s}^{-1}$ inflow contour. 
$\mathrm{T}+45.0 \mathrm{~h}$

Pre-fluctuation RI

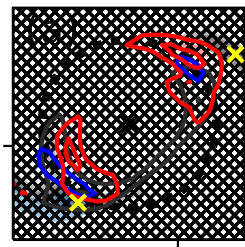

$\mathrm{T}+58.0 \mathrm{~h}, \mathrm{~W} 2$

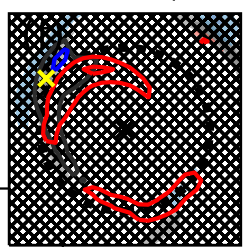

$\mathrm{T}+68.0 \mathrm{~h}, \mathrm{~S} 2$

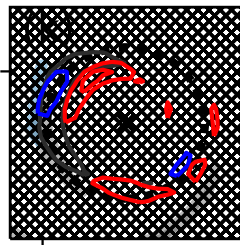

T'+77.0h ,W4

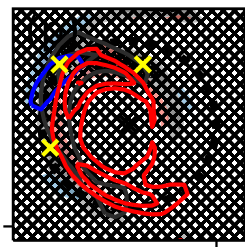

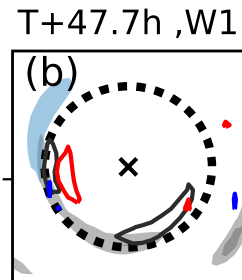
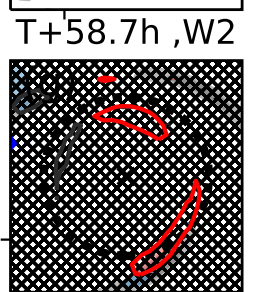

$\mathrm{T}+69.7 \mathrm{~h}, \mathrm{~W} 3$

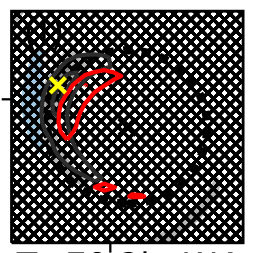

$\mathrm{T}+79.2 \mathrm{~h}, \mathrm{~W} 4$

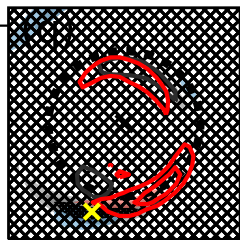

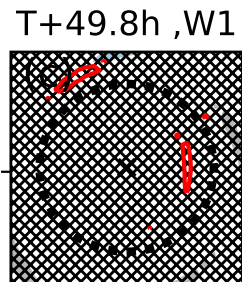
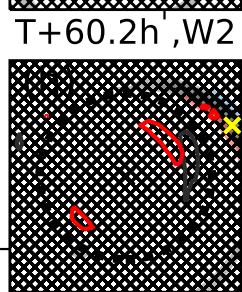

$T+72.2 h^{\prime}, W 3$
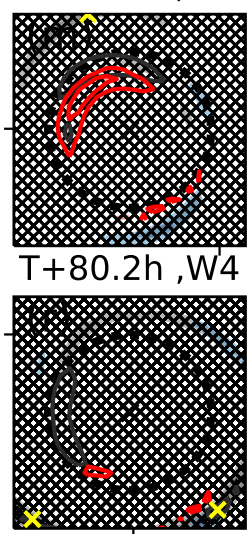
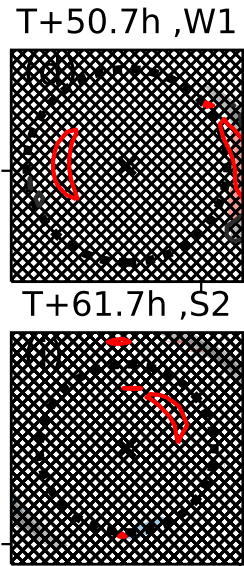

$\mathrm{T}+72.8 \mathrm{~h}, \mathrm{~S} 3$
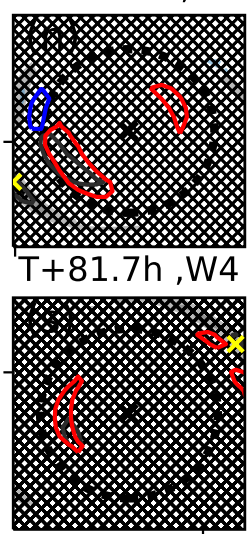
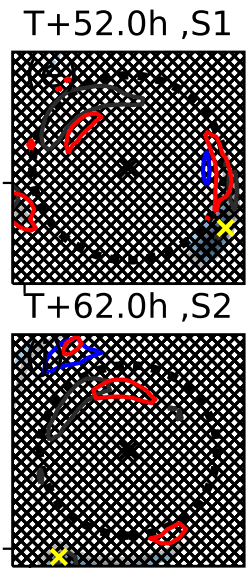

$\uparrow+73.7 \mathrm{~h}, \mathrm{~S} 3$
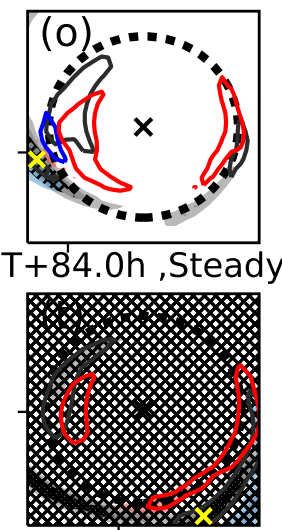

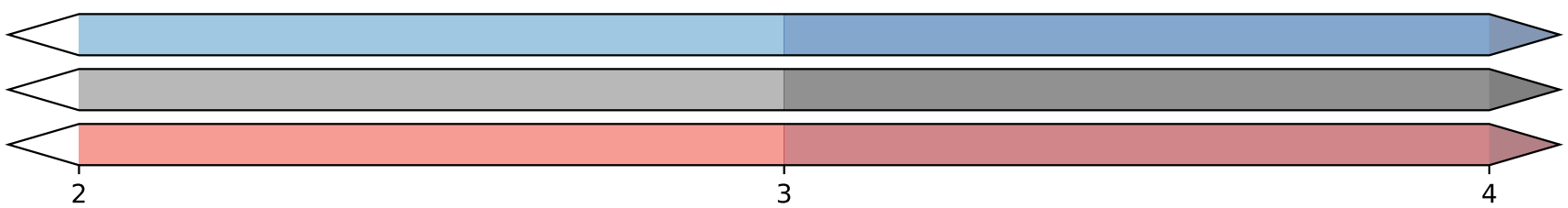

Figure 9. Pertubation vertical velocity $\left(\mathrm{m} \mathrm{s}^{-1}\right.$, shaded relative to the azimuthal mean), perturbation relative vorticity $\left(10^{-3} \mathrm{~s}^{-1}\right.$, coloured line contours) shown at the same times as in Fig. 5. Heights shown are $2532 \mathrm{~m}$ for the red shades/lines, $4963 \mathrm{~m}$ for the grey shades/lines, and $9934 \mathrm{~m}$ for the blue shades/lines. The centre of the TC is denoted by the cross and the RMW at $4963 \mathrm{~m}$ is indicated by the black dashed line. Black hatches represent regions where the maximum perturbation vertical velocity at any level exceeds $5 \mathrm{~m} \mathrm{~s}^{-1}$. Yellow crosses show the locations of locally high pertubation relative vorticity at $4963 \mathrm{~m}$ to indicate the location of VHT-like structures. 

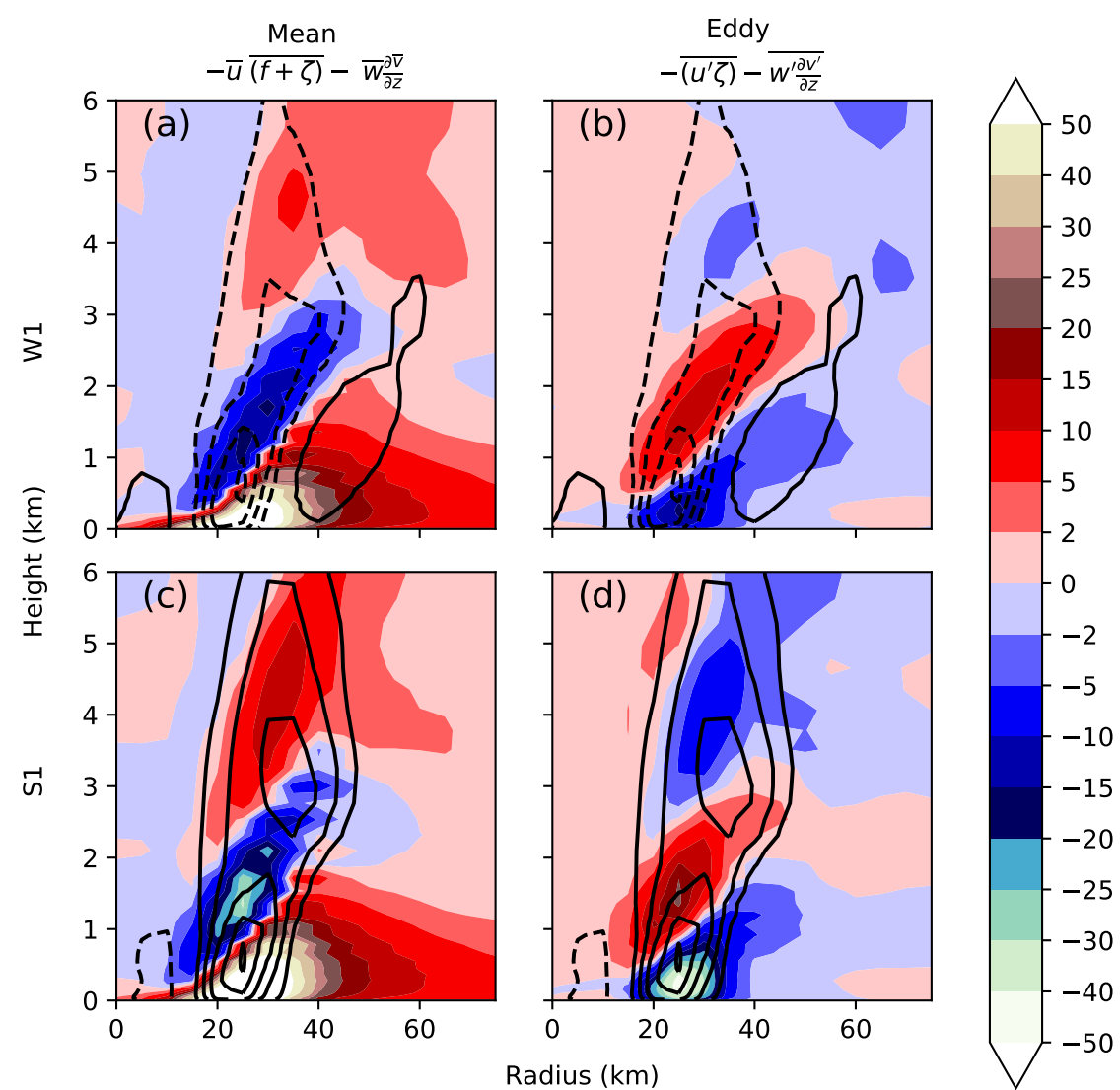

Figure 10. Colour shading shows the (a,c) mean and (b,d) eddy contributions to the tangential wind budget (see equation 3$)$ in $\mathrm{ms}^{-1} \mathrm{~h}^{-1}$. Line contours show the average tangential wind tendency in $2 \mathrm{~ms}^{-1} \mathrm{~h}^{-1}$ intervals with dashed contours indicating negative tendencies. The top row shows the composite for W1 (every 10 minute output in the W1 phase averaged over) while the bottom row shows the composite for S1 (every 10 minute output in the S1 phase averaged over). The frictional term (not shown) also contributes a large positive tangential tendency in the boundary layer. 


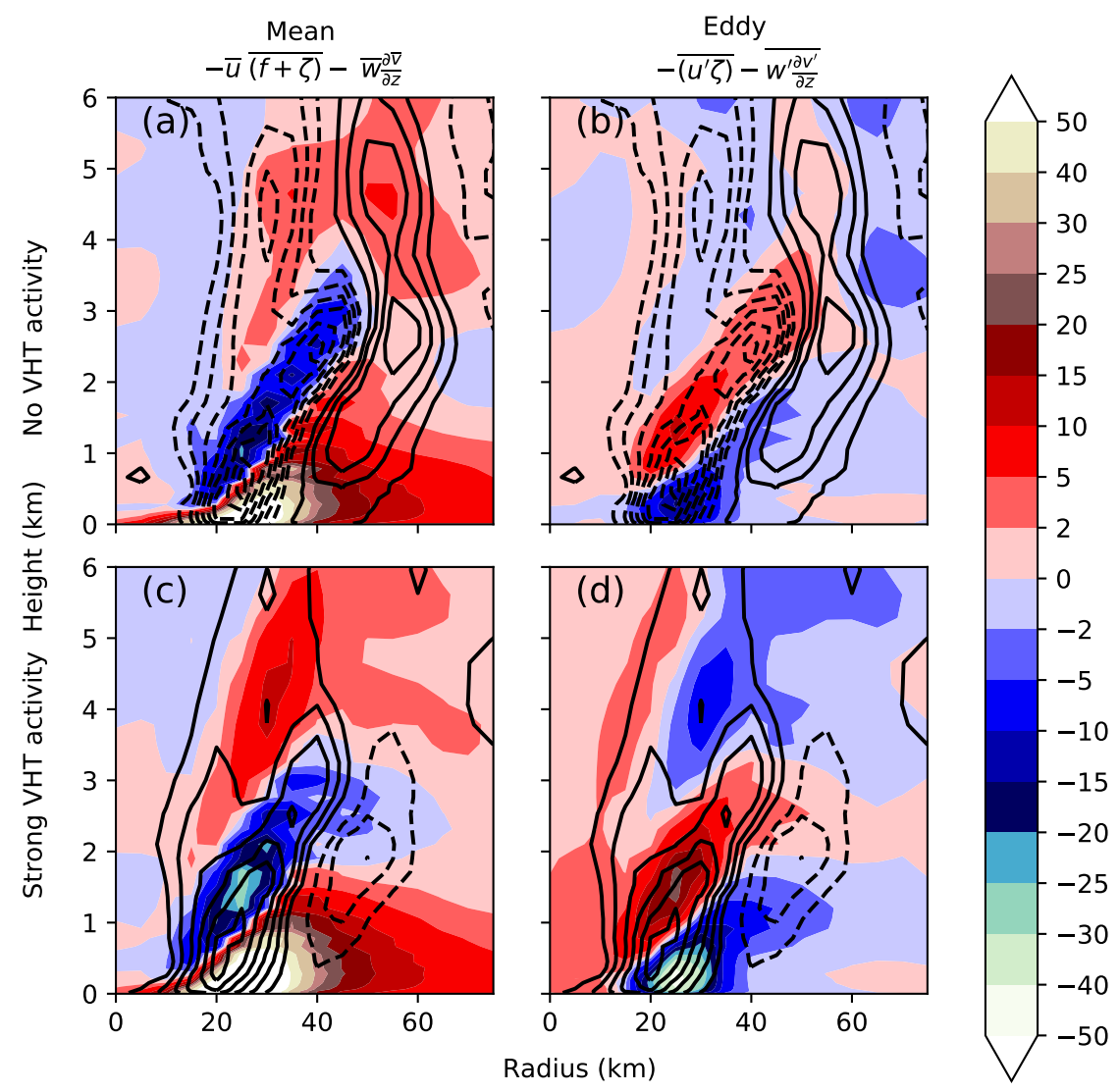

Figure 11. As with Fig. 10 but this time composites of no VHT activity (top row) and strong VHT activity (at least one VHT-like structure with ascent shading and vorticity contours at all three levels as in Fig. 9; bottom row). Composites are created by averaging any times in the W1 and S1 combined period with no distinction between weakening and strengthening periods (45.5 hours to 57.5 hours) that either have no VHT activity (top row) or strong VHT activity (bottom row). 


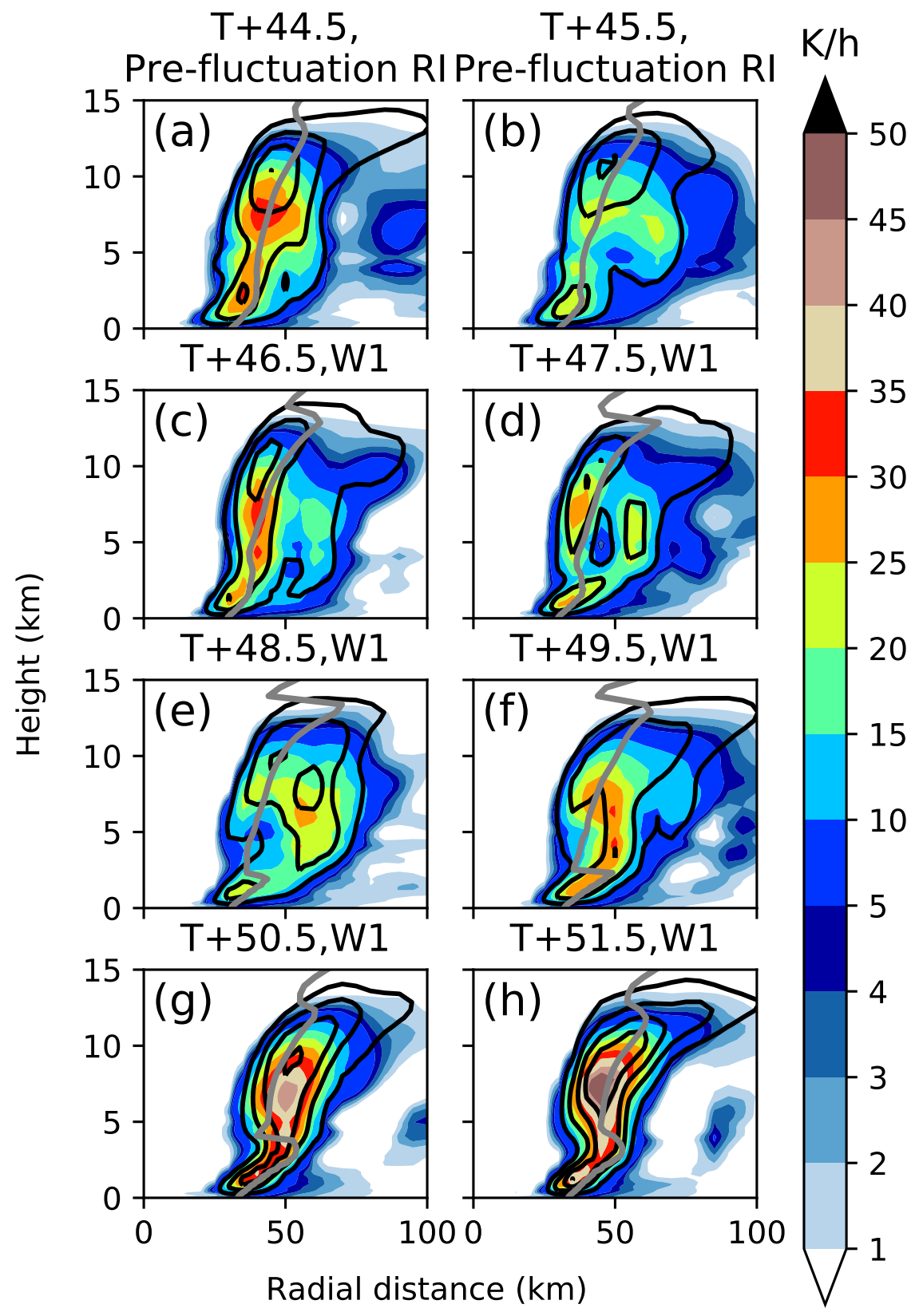

Figure 12. Diabatic heating (shading, $\mathrm{Kh}^{-1}$ ), vertical velocity (line contours) in intervals of $0.5 \mathrm{~m} \mathrm{~s}^{-1}$ before and during the first weakening phase W1. Also shown as a grey line is the RMW. 


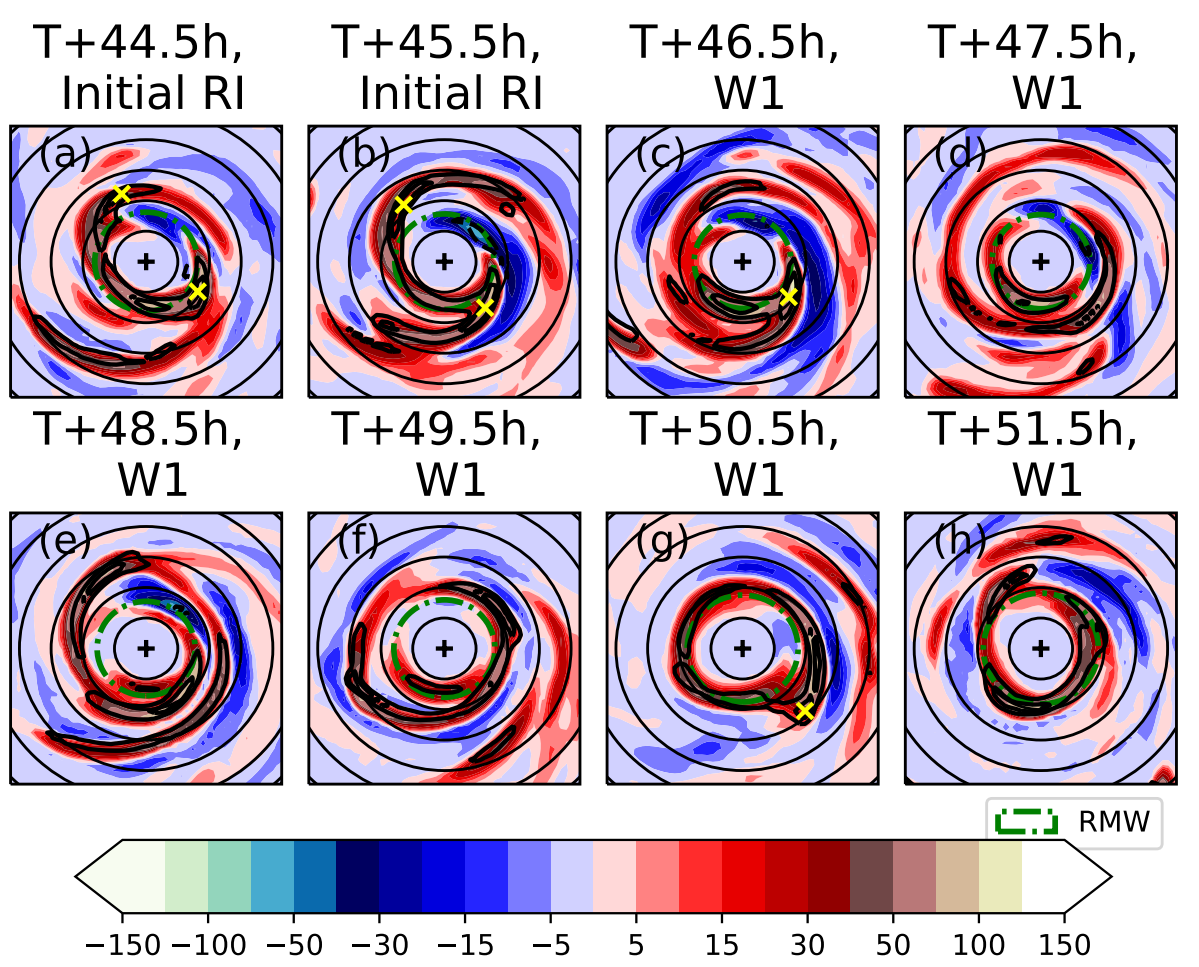

Figure 13. Diabatic heating ( $\mathrm{Kh}^{-1}$ shading) for height $4963 \mathrm{~m}$ before and during the first weakening phase W1. Vertical velocity contours in intervals of $2 \mathrm{~ms}^{-1}$. Yellow crosses indicate the location of the maximun local pertubation vertical velocity at the same level for any VHT-like structures as determined by criteria adapted fromn Smith and Eastin (2010). 


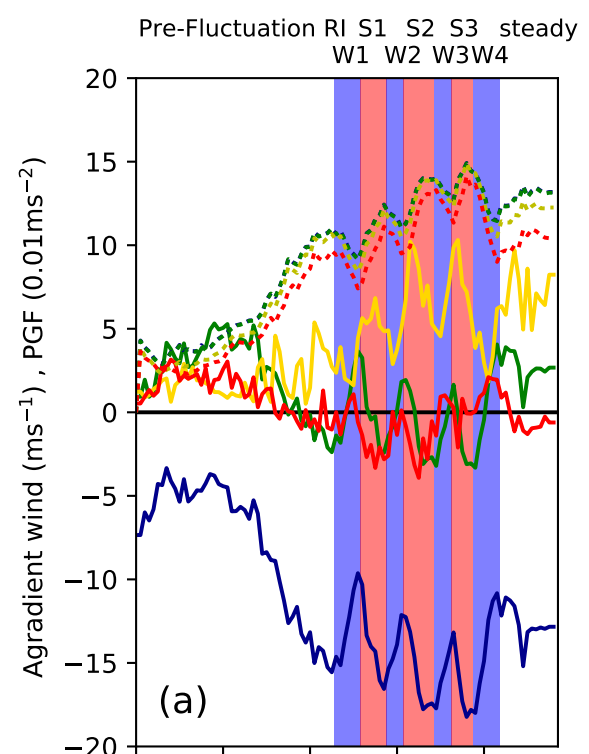

Pre-Fluctuation RI S1 S2 S3 steady
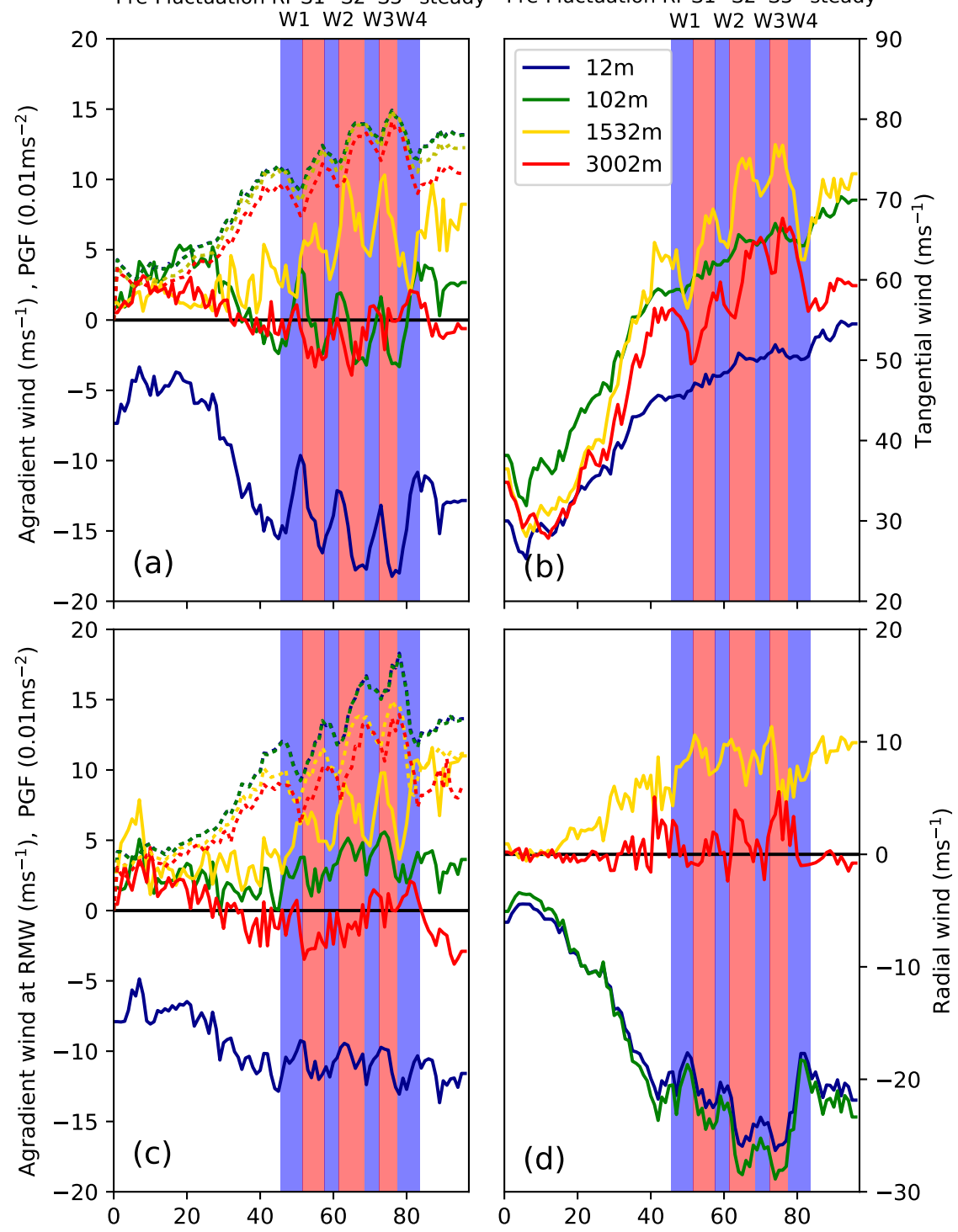

Time (h)

Figure 14. Left column shows azimuthally averaged agradient wind as a function of time ( $\mathrm{m} \mathrm{s}^{-1}$ ) for (a) a radius of $35 \mathrm{~km}$ and (c) at the RMW. The right column shows, for the $35 \mathrm{~km}$ radius, the azimuthally averaged (b) tangential and (d) radial winds ( $\mathrm{m} \mathrm{s}^{-1}$ ). The height of the lines are $12 \mathrm{~m}$ (blue), $102 \mathrm{~m}$ (green), $1902 \mathrm{~m}$ (orange) and $3002 \mathrm{~m}$ (red). Panels (a) and (c) also show the pressure gradient force (0.01m $\mathrm{s}^{-2}$, dashed lines) at selected levels. 

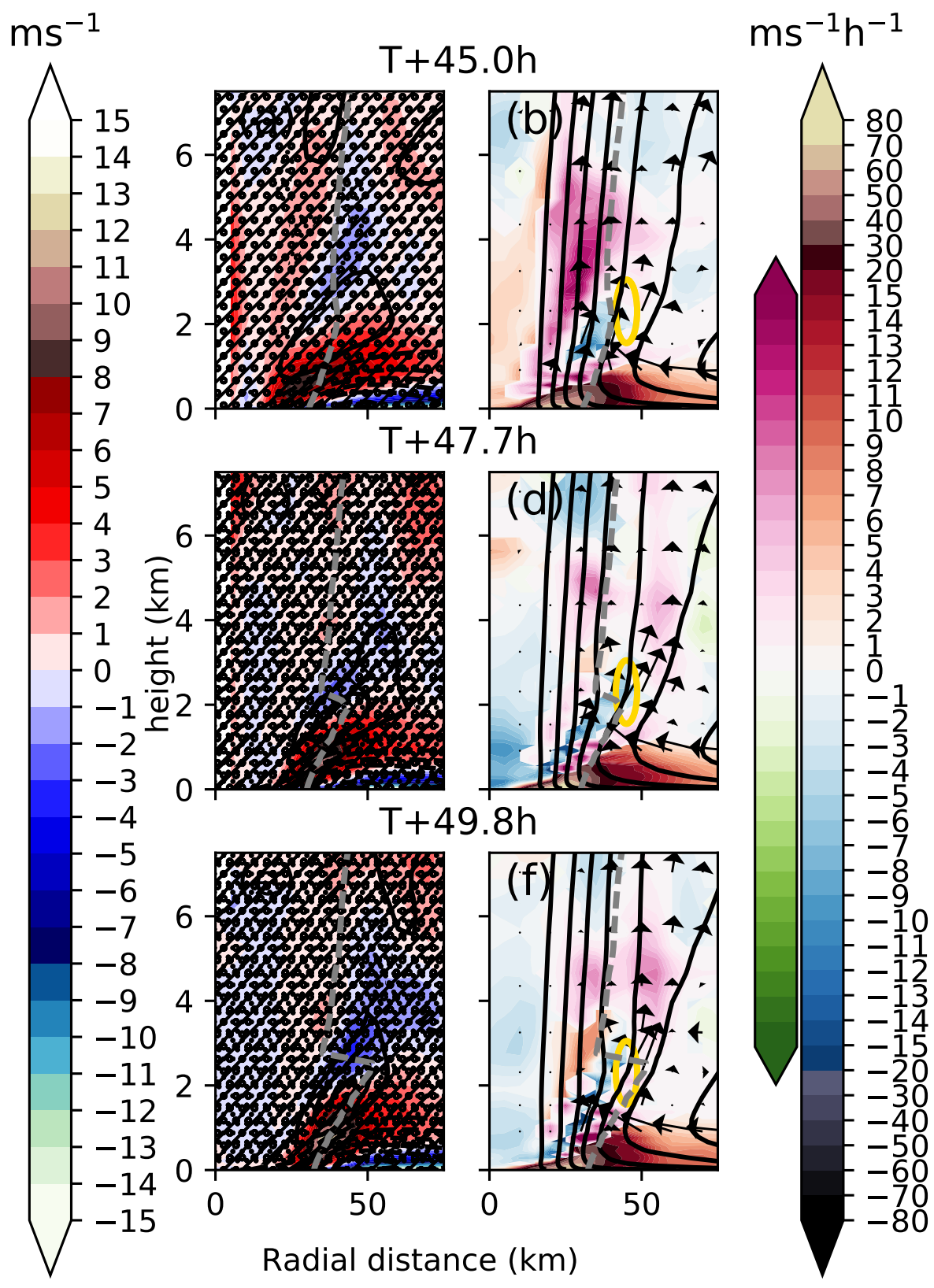

Figure 15. Left column shows, as a function of height and radius: the agradient wind (shading, $\mathrm{ms}^{-1}$ left colourbar), the radial wind in intervals of $4 \mathrm{~m} \mathrm{~s}^{-1}$ with dashed lines indicating negative values, the tendency in tangential wind as small dots showing $+2 \mathrm{~ms}^{-1} \mathrm{~h}^{-1}$, large dots showing $+4 \mathrm{~ms}^{-1} \mathrm{~h}^{-1}$, line hatches showing $-2 \mathrm{~ms}^{-1} \mathrm{~h}^{-1}$ and cross hatches showing $-4 \mathrm{~ms}^{-1} \mathrm{~h}^{-1}$. Right column shows angular momentum (lines in units of $5 \times 10^{-5} \mathrm{~m}^{2} \mathrm{~s}^{-1}$ ) and the secondary circulation as arrows in the plane of the cross section (with the boundary layer strong inflow omitted for clarity). The shading shows the contribution of the sum of the radial and vertical advection of angular momentum to the tangential wind budget. The colour scale used indicates which is the dominant term. If radial advection dominates over vertical advection then the blue/red shading is used and if vertical advection is dominant over radial advection then the green/purple scheme is used. For example green shading implies that the radial and vertiłd advection of angular momentum causes a negative tangential wind tendency and that the vertical term dominates. Also shown is RMW as the dashed grey line. The times shown in (a,b) are T+45 h, $(\mathrm{c}, \mathrm{d})$ $\mathrm{T}+47.4 \mathrm{~h}$, and $(\mathrm{e}, \mathrm{f}) \mathrm{T}+49.8 \mathrm{~h}$ (the first three panels in Fig. 9). A region of interest is denoted by the yellow ellipse. 
https://doi.org/10.5194/wcd-2021-81

Preprint. Discussion started: 3 January 2022

(c) Author(s) 2022. CC BY 4.0 License.

(c) (i)

Weather and

Climate Dynamics

Discussions
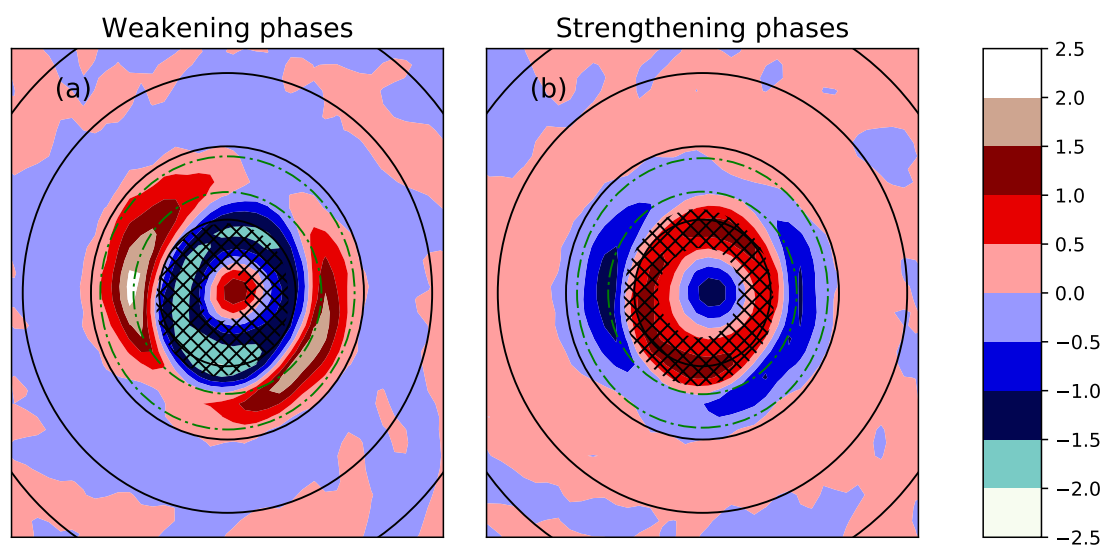

Figure 16. Composite PV tendencies $\left(\mathrm{PVUh}^{-1}\right.$ shading) at $1532 \mathrm{~m}$ across all weakening and strengthening phases in the five ensembles with distinct intensity fluctuations. Green dashed lines show the full range of RMWs at the same level. Hatching indicates regions where the average PV exceeds 30 PVU. Black circles show $25 \mathrm{~km}$ radial intervals. 


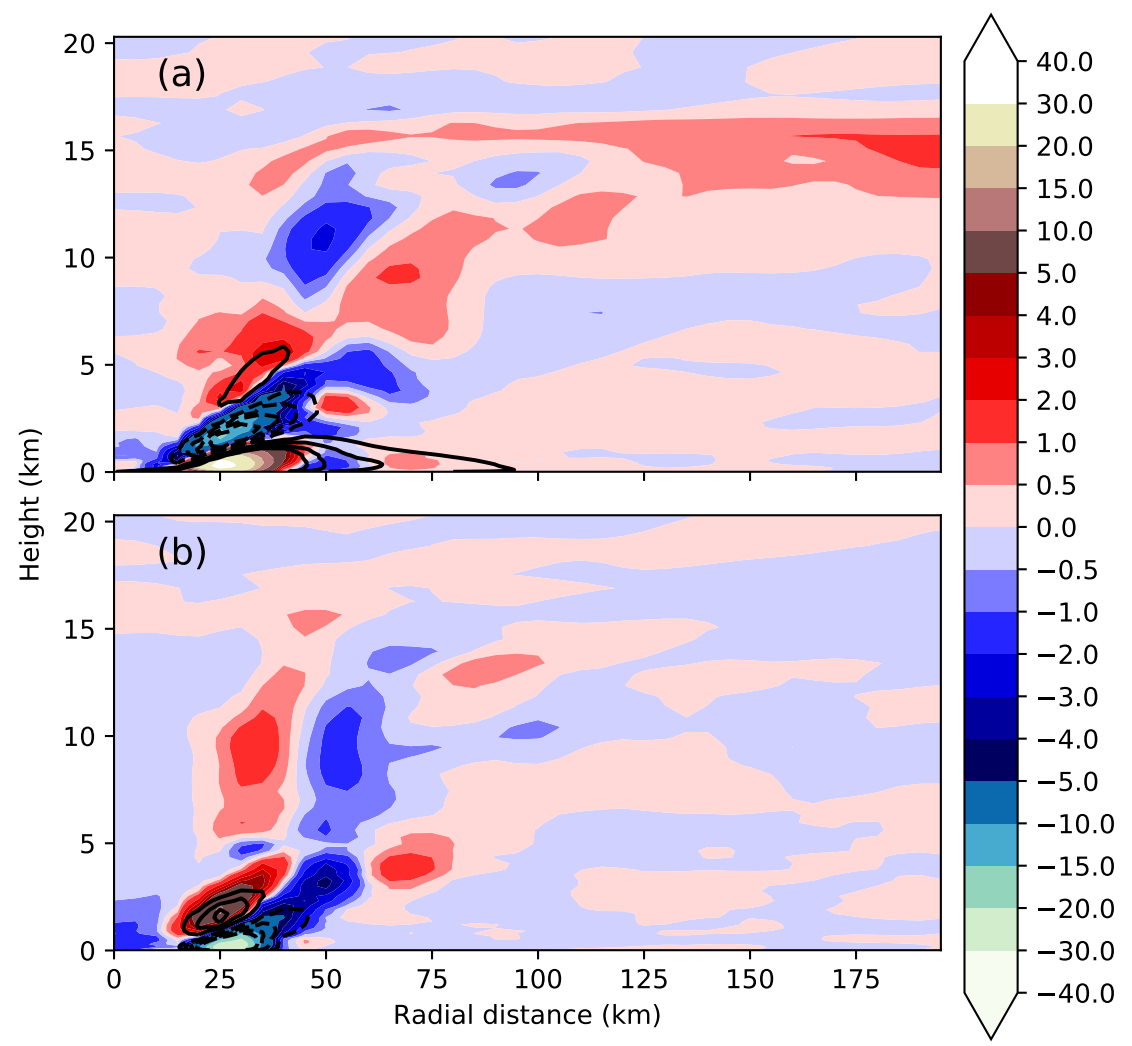

Figure 17. Absolute angular momentum budget composites showing: (a) mean advection of angular momentum, and (b) eddy advection of angular momentum . Colour shading shows the difference in tangential wind tendency between the strengthening phase composite and the weakening phase composite in $\mathrm{ms}^{-1} \mathrm{~h}^{-1}$. Line contours $\left(5 \mathrm{~ms}^{-1} \mathrm{~h}^{-1}\right.$ intervals, dashed lines imply negative values) show a composite of the contribution to tangential wind budget during all the strengthening phases (for example in subplot a at around $50 \mathrm{~km}$ there is a strongly positive tangential wind tendency from the mean term over all the strengthening phases). 
(a) End of strengthening phase

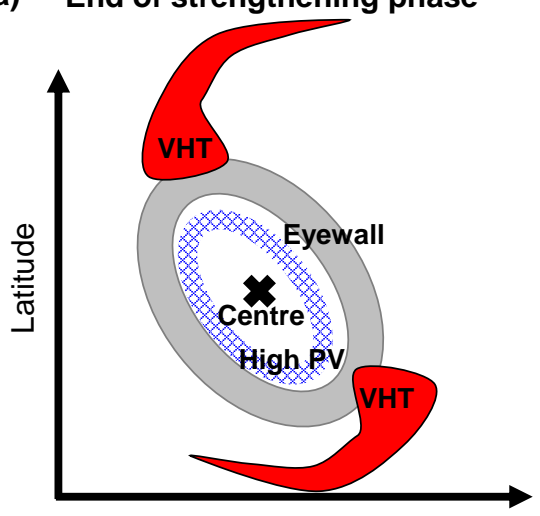

(c) Middle of weakening phase

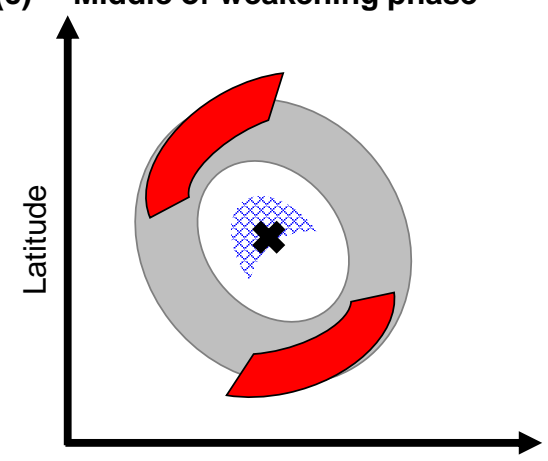

(e) Start of strengthening phase

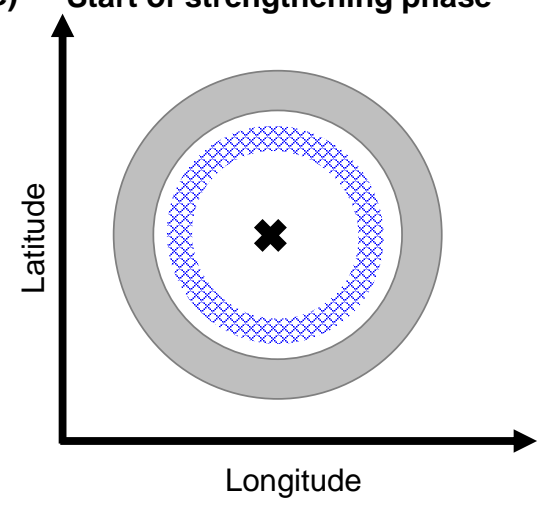

(b)

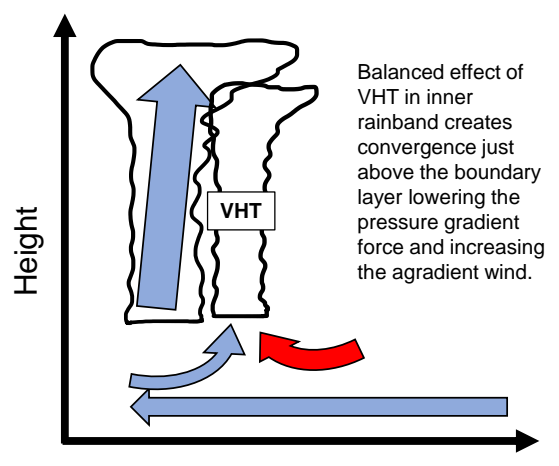

(d)

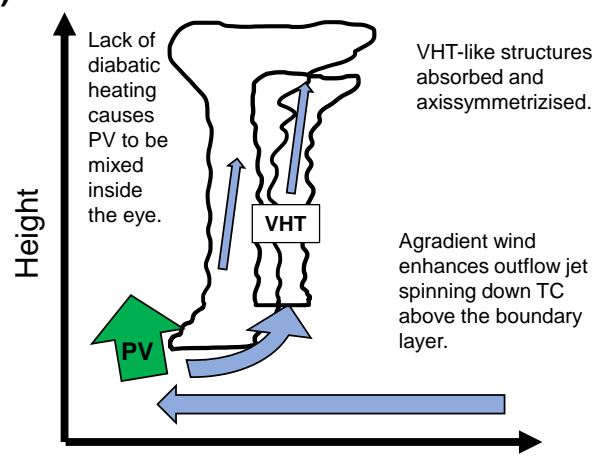

(f)

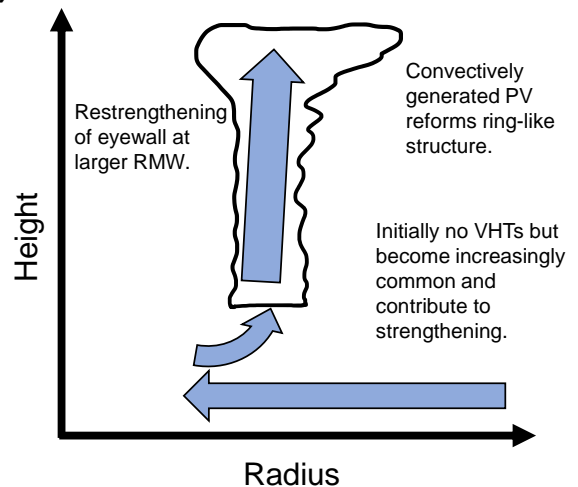

Figure 18. Schematic outlining the proposed mechanism for the fluctuations modelled during the rapid intensification of Hurricane Irma during: $(a, b)$ the end of a strengthening phase, $(c, d)$ the middle of a weakening phase and $(e, f)$ the start of the strengthening phase. Left column shows the horizontal structure of the storm including VHT-like structures (red), eyewall convection (grey) and regions of high PV (blue hatched). Right column shows the azimuthally averaged structure of the storm at each stage with arrows indicating the direction of the secondary circulation (larger arrows imply stronger flow). A red arrow in panel $b$ indicates that the inflow is a balanced response to the VHT-like structure. A green arrow in d shows the direction of transport of high PV. In (b,d) the VHT-like structure is indicated by a 2nd cloud outside of the eyewall. 